ARTICLE

\title{
Dihydroxyacetone valorization with high atom efficiency via controlling radical oxidation pathways over natural mineral-inspired catalyst
}

Jinling Wang (1) 1,2,6, Xingchao Dai ${ }^{3,4,6}$, Hualin Wang1, Honglai Liu², Jabor Rabeah (D) ${ }^{3}$, Angelika Brückner (D) ${ }^{3 凶}$, Feng Shi (i) ${ }^{4}$, Ming Gong ${ }^{5} \&$ Xuejing Yang (iD) ${ }^{1 凶}$

Diminishing fossil fuel resources and calls for sustainability are driving the urgent need for efficient valorization of renewable resources with high atom efficiency. Inspired from the natural goethite mineral with $\mathrm{Mn}$ paragenesis, we develop cost-effective $\mathrm{MnO}_{2}$ /goethite catalysts for the efficient valorization of dihydroxyacetone, an important biomass-based platform molecule, into value-added glycolic acid and formic acid with $83.2 \%$ and $93.4 \%$ yields. The $\mathrm{DHA}$ substrates first undergo $\mathrm{C}-\mathrm{C}$ cleavage to selectively form glycolic acid and hydroxymethyl $\left(\cdot \mathrm{CH}_{2} \mathrm{OH}\right)$ radicals, which are further oxidized into formic acid. The kinetic and isotopic labeling experiments reveal that the catalase-like activity of $\mathrm{MnO}_{2}$ turns the oxidative radicals into oxygen, which then switches towards a hydroxymethyl peroxide (HMOO) pathway for formic acid generation and prevents formic acid over-oxidation. This nature-inspired catalyst design not only significantly improves the carbon efficiency to $86.6 \%$, but also enhances the oxygen atom utilization efficiency from $11.2 \%$ to $46.6 \%$, indicating a promising biomass valorization process.

\footnotetext{
${ }^{1}$ National Engineering Laboratory for Industrial Wastewater Treatment, East China University of Science and Technology (ECUST), Shanghai 200237, China. ${ }^{2}$ State Key Laboratory of Chemical Engineering, ECUST, Shanghai 200237, China. ${ }^{3}$ Leibniz-Institut für Katalyse e.V. an der Universität Rostock (LIKAT), 18059 Rostock, Germany. ${ }^{4}$ State Key Laboratory for Oxo Synthesis and Selective Oxidation, Lanzhou Institute of Chemical Physics, Chinese Academy of Sciences, Lanzhou 730000, China. ${ }^{5}$ Department of Chemistry, Fudan University, Shanghai 200438, China. ${ }^{6}$ These authors contributed equally: Jinling Wang, Xingchao Dai. 凶email: angelika.brueckner@catalysis.de; xj.yang@ecust.edu.cn
} 
T he global decline of fossil fuel resources and subsequent climate change issues have accelerated the need for renewable energy and sustainable resources. As a result, the co-production of chemicals with a high atom economy is being pursued with enthusiasm ${ }^{1-6}$. Biodiesel is a renewable bio-derived fuel with steadily increasing production over the years but has led to the over-supply of crude glycerol with relatively low utilization efficiency $^{7-11}$. 1,3-dihydroxyacetone (DHA), which can be obtained via the catalytic oxidation or fermentation of glycerol and ketose ${ }^{9,12}$, is listed as one of the most important C3 platform molecules. DHA can be converted to $\mathrm{C} 2$ and $\mathrm{C} 1$ chemicals via selective $\mathrm{C}-\mathrm{C}$ cleavage ${ }^{9,13}$, which enriches the product and value chain. For instance, selective $\mathrm{C}-\mathrm{C}$ cleavage of DHA can simultaneously produce glycolic acid (GA) and formic acid (FA) with high atomic efficiency ${ }^{10,14-16}$, in which GA is an important intermediate for the synthesis of personal care products and FA is often used in the food and leather industry or as a source of formyl groups and a hydrogen storage carrier ${ }^{17,18}$.

Hydroxyl radicals (HO-) with the second strongest oxidative power $\left(\mathrm{E}^{\mathrm{O}}\left(\mathrm{OH} / \mathrm{H}_{2} \mathrm{O}\right)=2.80 \mathrm{~V} / \mathrm{SHE}\right)^{19,20}$, often generated by Fenton chemistry, have been proven as a powerful tool for the oxidative $\mathrm{C}-\mathrm{C}$ cleavage of organic compounds, which guides the development of biomass upgrading, plastics degradation, wastewater treatment, and many other applications ${ }^{21-24}$. Recently, $\mathrm{Cu} /$ $\mathrm{Al}_{2} \mathrm{O}_{3}$ catalysts with isolated active sites were found to split $\mathrm{H}_{2} \mathrm{O}_{2}$ into $\mathrm{HO}$. that selectively cleaves the $\mathrm{C}-\mathrm{C}$ bonds in DHA to produce GA with excellent yields, and formamides and formates

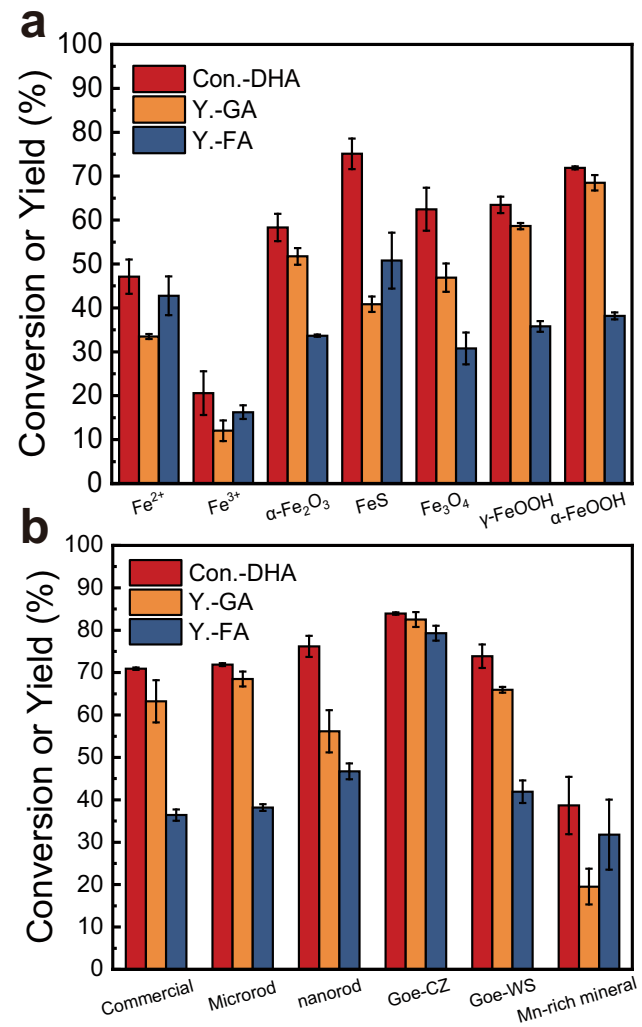

Fig. 1 Catalytic performance screening of iron-based catalysts. a Catalytic activity for DHA oxidation over Fe-based ions and different Fe-containing minerals. b Catalytic activity for DHA oxidation over different goethite and Fe-containing $\mathrm{Mn}$-rich minerals. The commercially available goethite (Sigma, 30-50 mesh) was used after grinding to more than 200 mesh. Reaction conditions: catalyst $30 \mu \mathrm{mol}, \mathrm{DHA} 1 \mathrm{mmol}, \mathrm{H}_{2} \mathrm{O}_{2} 0.2 \mathrm{~mL}$ (30 wt\% $\mathrm{H}_{2} \mathrm{O}_{2}$ aqueous), $25^{\circ} \mathrm{C}, 400 \mathrm{rpm}, 24 \mathrm{~h}$. Error bars represent standard deviations from triplicate experiments. can be co-produced with GA efficiently when amines and alcohols are used as the co-substrates to stabilize and trap the FA intermediates ${ }^{13}$. However, this system still requires high $\mathrm{H}_{2} \mathrm{O}_{2}$ dosage (6 $\mathrm{mmol} \mathrm{H}_{2} \mathrm{O}_{2}$ for $1 \mathrm{mmol}$ DHA) to hedge against its inefficient decomposition leading to the low $\mathrm{H}_{2} \mathrm{O}_{2}$ utilization efficiency, while the high $\mathrm{H}_{2} \mathrm{O}_{2}$ dosage also induces the overoxidation of products toward a low carbon efficiency. This dilemma is, in fact, a general problem in selective oxidation systems using $\mathrm{H}_{2} \mathrm{O}_{2}$ as an oxidant due to the transient kinetics and reactive nature of oxygen-centered radicals, which results in significant difficulties for $\mathrm{H}_{2} \mathrm{O}_{2}$-based oxidation with high atom efficiency ${ }^{25,26}$

Compared to the $\mathrm{C}-\mathrm{C}$ bond in alkane $(83-90 \mathrm{kcal} / \mathrm{mol})$, the $\mathrm{C}_{\alpha}-\mathrm{C}$ bond in DHA is relatively weak $(\sim 80 \mathrm{kcal} / \mathrm{mol}$ for acetone $)^{27}$, but is subject to keto-enol tautomerism ${ }^{28,29}$, which complicates the oxidative $\mathrm{C}-\mathrm{C}$ cleavage of DHA. Under the attack of oxidative radicals, DHA could be oxidized to generate various organic radicals, making the controlled conversion to targeted chemicals difficult, while requiring a clear understanding of their precise fate and efficient regulation of radical pathways. For the present study, we were inspired from natural goethite minerals that are capable of cleaving the $\mathrm{C}-\mathrm{C}$ bonds of organic compounds ${ }^{30,31}$. We succeeded in synthesizing a $\mathrm{MnO}_{2}$-attached goethite catalyst that can co-produce GA and FA with high yields. This system decreases the $\mathrm{H}_{2} \mathrm{O}_{2}$ stoichiometric ratio by a factor of 3 to achieve high atom efficiency, particularly with the highest oxygen atom efficiency ever reported. We found that the introduction of $\mathrm{MnO}_{2}$ can not only promote $\mathrm{HO}$. generation and $\mathrm{C}-\mathrm{C}$ cleavage, but also mediate the chain reaction to inhibit FA overoxidation. We are convinced that our strategy of using natureinspired abundant $\mathrm{Fe} / \mathrm{Mn}$-based catalysts to selectively oxidize biomass-derived molecules into value-added products can boost the future development of biomass valorization technologies significantly.

\section{Results}

Catalytic performance of iron-bearing minerals and natural goethite-inspired catalysts. The typical iron-bearing minerals in the geochemical cycling of $\mathrm{Fe}$, including hematite $\left(\alpha-\mathrm{Fe}_{2} \mathrm{O}_{3}\right)$, pyrite $\left(\mathrm{FeS}_{2}\right)$, magnetite $\left(\mathrm{Fe}_{3} \mathrm{O}_{4}\right)$, goethite $(\alpha-\mathrm{FeOOH})$ and lepidocrocite $(\gamma-\mathrm{FeOOH})$, and the homogeneous Fenton catalysts $\left(\mathrm{Fe}^{2+}\right.$ and $\left.\mathrm{Fe}^{3+}\right)$ were first screened for the selective oxidation of DHA. As shown in Fig. 1a, low DHA conversions of $20.0 \%$ and $47.1 \%$ were observed in the homogeneous $\mathrm{Fe}^{3+}$ and $\mathrm{Fe}^{2+}$ systems, respectively, indicating their weak activities of $\mathrm{C}-\mathrm{C}$ bond cleavage. Although pyrite afforded the highest conversion of DHA (75.1\%) among Fe-bearing minerals, it exhibited only moderate GA and FA yields and was almost completely dissolved after $24 \mathrm{~h}$ of reaction (the leaching ratio of $\mathrm{Fe}>90 \%$, Supplementary Table 1). Taking into combined account of the DHA conversion and GA/FA yields, goethite outperformed other minerals with 71.9\% DHA conversion, $68.5 \%$ GA yield, and $38.2 \%$ FA yield and maintained a satisfactory stability during the reaction. Further, we synthesized goethite with different sizes of microrods and nanorods to regulate its catalytic activity. Their corresponding structures were confirmed by SEM and XRD (Supplementary Fig. 1, 2). The conversion of DHA was improved from 71.9 to $76.2 \%$ when the size of goethite rods was reduced to nanoscale (Fig. 1b). Meanwhile, the GA yield decreased, indicating the difficulty of the size regulation towards high-yield GA and FA production under high DHA conversion.

As the most thermodynamically stable and the most abundant Fe-bearing mineral ${ }^{32}$, goethite is widely found in soils of the temperate climate, marine and lake sediments and can occur in variable structures, such as intergrown $\mathrm{Fe}$-/Mn-oxides, calcite and 
clay minerals or other atoms such as isomorphous crystal elements and trace metals ( $\mathrm{Al}, \mathrm{Mn}$ and etc.) can substitute for the $\mathrm{Fe}$ atoms $\mathrm{s}^{33-35}$. To investigate these possible contributions of the unique natural structures, two natural goethite minerals, and a natural Mn-rich mineral were directly extracted from a mine and chosen for the selective oxidation of DHA. As shown in Fig. 1b, Goe-CZ, one of the natural goethites, showed a significant increase in GA and FA yield to 82.5 and $79.3 \%$ respectively (Fig. 1b). This serendipitous result impelled us to comprehensively characterize its composition and structure. Notably, the ICP analysis detected the presence of $\sim 1.1 \mathrm{wt} \%$ of $\mathrm{Mn}$ in Goe-CZ, but not in any other goethites. In the natural environment, $\mathrm{Mn}$ can be substituted for Fe in the goethite structure by forming the isostructural groutite $(\alpha-\mathrm{MnOOH})$, nsutite $\left(\gamma-\mathrm{MnO}_{2}\right)$, or ramsdellite $\left(\mathrm{r}-\mathrm{MnO}_{2}\right)^{34,36}$. With the increase of the $\mathrm{Mn} / \mathrm{Fe}$ ratio, new separate $\mathrm{Mn} / \mathrm{Fe}$ - or $\mathrm{Mn}$-bearing phases, such as jacobsite $\left(\mathrm{MnFe}_{2} \mathrm{O}_{4}\right)$, hausmannite $\left(\mathrm{Mn}_{3} \mathrm{O}_{4}\right)$, or pyrolusite $\left(\beta-\mathrm{MnO}_{2}\right)$, may appear together with goethite ${ }^{36}$. The $\mathrm{Mn}$ distribution in the Goe-CZ was further investigated due to its possible contribution to catalytic performance. No perceptible diffraction peaks of Mn-containing phases were observed in XRD patterns (Fig. 2a), but the nanocrystalline hausmannite and pyrolusite phases were successfully identified in the HRTEM images of the Goe-CZ sample (Supplementary Fig. 3). The XPS peaks at $641.5 \mathrm{eV}$ can be attributed to Mn $2 p_{3 / 2}$ signal of $\mathrm{Mn}$ (IV) species (Fig. 2b). The microscopic morphological analysis provided direct visual evidence for the proposed Mn distributions. SEM images revealed that the mineral is composed of $0.1-0.3 \mathrm{~mm}$ flake-like macroparticles, but microscopically forms a stacking of $<1 \mu \mathrm{m}$ rod-like microparticles (Supplementary Fig. 4). According to the EPMA analysis with high spatial resolution (Fig. 2d), Mn was largely absent on most Goe-CZ surfaces, while a high Mn content was detected on some micron-sized particles, confirming the intergrowth of Mn-bearing phases with goethite. Besides, the Mn substitution into the goethite lattice was also observed in some particles, as indicating the overlap of $\mathrm{Fe}$ and Mn EDS signals at the rod edges (Fig. 2e).

As illustrated in Fig. 2f, the above characterizations clearly showed the two forms of $\mathrm{Mn}$ in the natural goethite (Goe-CZ), which inspired us to mimic the natural structure of Goe-CZ. We directly added the $\mathrm{Mn}$ nitrate salt to the precursors of goethite $\left(\mathrm{Fe}(\mathrm{NO})_{3}\right)$ in the synthesis of goethite to mimic the substitution of isostructural groutite, nsutite, or ramsdellite in natural goethite, denoted as Mn-doped goethite (Mn/Goe). As shown in Supplementary Fig. 5, only the goethite phase was present in the Mn/Goe sample and the successful Mn doping in Mn/Goe was confirmed from ICP result (1.21\% of Mn). The overlaid Mn $2 p_{3 / 2}$ spectra of Goe-CZ and Mn/Goe showed a clear difference in the peak shapes (Supplementary Fig. 6). The Mn 2p $3 / 2$ signal of $\mathrm{Mn} / \mathrm{Goe}$ was fitted to $\mathrm{Mn}$ (III) $(641.5 \mathrm{eV})$ and $\mathrm{Mn}(\mathrm{IV})(639.9 \mathrm{eV})$ species (Supplementary Fig. 7). The intergrowth of $\mathrm{Mn} / \mathrm{Fe}-$ bearing phases was mimicked by mechanical mixing the asprepared jacobsite, commercial hausmannite, or pyrolusite with as-synthesized goethite microrods, denoted as jacobsite-attached goethite (jacobsite/Goe), hausmannite-attached goethite (hausmannite/Goe), and pyrolusite-attached goethite (pyrolusite/Goe), respectively. Similar to the Goe-CZ, there are no diffraction peaks assigned to $\mathrm{Mn} / \mathrm{Fe}$-bearing phases in any of the three samples (Supplementary Fig. 8), which should be ascribed to their low contents and high dispersion. Based on these results, we can conclude that the $\mathrm{Mn}$ distributions in natural Goe-CZ were largely reproduced by the doped and mixed samples, although there are still differences in the relative intensities of the diffraction peaks and the Mn valence states.

Selective oxidation of DHA was performed with the natural goethite-inspired mimic catalysts. Obviously, these catalysts with different $\mathrm{Mn}$ distributions showed significant differences in the catalytic activity. As shown in Fig. 2g, Mn/Goe showed only slightly improved yields compared to the pure goethite, while the three $\mathrm{MnO}_{x}$-attached goethites showed significant improvement in the catalytic performance, in which the GA/FA yields $(84.3 \%$ for GA and $90.8 \%$ for $\mathrm{FA}$ ) in $\mathrm{MnO}_{2}$ /Goe even surpassed natural Goe-CZ. This indicates that the reaction benefits from $\beta-\mathrm{MnO}_{2}$ as a separate crystal phase. The control experiments without goethite exhibited lower GA and FA yields (Supplementary Fig. 9), which demonstrated the critical synergy between goethite and $\beta-\mathrm{MnO}_{2}$. By screening reaction parameters like reaction time and $\mathrm{H}_{2} \mathrm{O}_{2}$ concentration, we pinned down an optimal condition of $2 \mathrm{mmol}$ of $\mathrm{H}_{2} \mathrm{O}_{2}$ for $24 \mathrm{~h}$ for the highest activity and selectivity (Supplementary Fig. 10). No obvious increase in GA and FA yields was observed under prolonged reaction time, and the GA and FA yields rose under relatively low $\mathrm{H}_{2} \mathrm{O}_{2}$ dosage but started to stagnate and even gradually decrease at high concentrations $(>2.0 \mathrm{mmol})$ due to the over-oxidation of products. However, under $\mathrm{O}_{2}$-rich conditions $\left(\mathrm{O}_{2}=1.2 \mathrm{MPa}\right)$ the amount of $\mathrm{H}_{2} \mathrm{O}_{2}$ dosage could be further reduced to $1.8 \mathrm{mmol}$ without a noticeable decrease in the GA and FA yield (Supplementary Fig. 11).

$\mathrm{MnO}_{2}$ particles profoundly impact on the DHA conversion, and their effect was then studied and optimized. The introduction of trace $\mathrm{MnO}_{2}(0.1 \mathrm{wt} \%$ of $\mathrm{Mn}$ in goethite) significantly improved the $\mathrm{H}_{2} \mathrm{O}_{2}$ decomposition and catalytic DHA conversion, but the reactivity remained nearly unchanged as the $\mathrm{MnO}_{2}$ ratio varied from $0.1 \mathrm{wt} \%$ to $5.0 \mathrm{wt} \%$ (Fig. 3a). The highest yield of GA and FA could reach 83.2 and $93.4 \%(\mathrm{Mn}=1.0 \mathrm{wt} \%)$, which outperformed the reported $\mathrm{Cu} / \mathrm{Al}_{2} \mathrm{O}_{3}$ system by $52.4 \%$ with respect to FA yield ${ }^{13}$. The improved FA yield could lead to a carbon atom efficiency of $86.6-10.2 \%$ higher than the $\mathrm{Cu} / \mathrm{Al}_{2} \mathrm{O}_{3}$ systemwhile the $\mathrm{CO}_{2}$ yield was drastically reduced from $18.2 \%$ in $\mathrm{Cu} /$ $\mathrm{Al}_{2} \mathrm{O}_{3}$ to $1.3 \%$ by avoiding the excessive oxidation of FA (Fig. 3b). This atom efficiency could be even higher due to a small percentage of unbalanced products $(2.2-7.8 \%)$. In addition to carbon efficiency, the utilization of $\mathrm{H}_{2} \mathrm{O}_{2}$ was also drastically improved by using less than a third of the $\mathrm{H}_{2} \mathrm{O}_{2}$, reaching an overall atom efficiency of $67.2 \%$ compared to $19.4 \%$ in $\mathrm{Cu} / \mathrm{Al}_{2} \mathrm{O}_{3}$ system. In particular, oxygen atom utilization of this catalyst impressively reached $44.2 \%$, and could further increase to $46.6 \%$ when the amount of $\mathrm{H}_{2} \mathrm{O}_{2}$ dosage was reduced to $1.8 \mathrm{mmol}$ under $\mathrm{O}_{2}$-rich conditions, which is at least two-fold higher than the highest heterogeneous oxidation processes using $\mathrm{H}_{2} \mathrm{O}_{2}$ as the oxidant (Fig. 3c and Supplementary Table 2) $13,26,37-46$. In industrial-scale chemical production that uses $\mathrm{H}_{2} \mathrm{O}_{2}$ as an oxidant, $\mathrm{H}_{2} \mathrm{O}_{2}$ cost is usually one of the main economic factors. Therefore, these chemical production processes are generally coupled with $\mathrm{H}_{2} \mathrm{O}_{2}$ synthesis plants, which are generally less expensive when considering the high production and transportation costs of commercial $\mathrm{H}_{2} \mathrm{O}_{2}$ (USD $0.43-2.87 \mathrm{~kg}^{-1}$ for production $\left(27.5-50\right.$ wt $\left.\% \mathrm{H}_{2} \mathrm{O}_{2}\right)$ and USD $2.87 \mathrm{~km}^{-1}$ for transportation $)^{47-49}$. The significant reduction of $\mathrm{H}_{2} \mathrm{O}_{2}$ consumption in this system can indisputably save the cost of $\mathrm{H}_{2} \mathrm{O}_{2}$ plant construction and its corresponding maintenance, thereby increasing the overall economic efficiency of the process. In addition, our biomass-based process also includes carbon emission reduction potential, which is also may be economically advantageous from a sustainability point of view. When the percentage of $\mathrm{MnO}_{2}$ reached $>5 \%, \mathrm{H}_{2} \mathrm{O}_{2}$ decomposition dominated over the DHA conversion, decreasing yields of GA and FA. We also examined the effect of $\mathrm{MnO}_{2}$ on the homogeneous Fenton systems for DHA oxidation. However, the $\mathrm{Fe}^{2+}$ and $\mathrm{Fe}^{3+}$ systems only showed slightly higher DHA conversion and FA yield upon the addition of different $\mathrm{MnO}_{2}$ amounts, indicating that the homogeneous Fenton activity cannot be easily promoted by $\mathrm{MnO}_{2}$ (Supplementary Fig. 12). Further, we extended this 

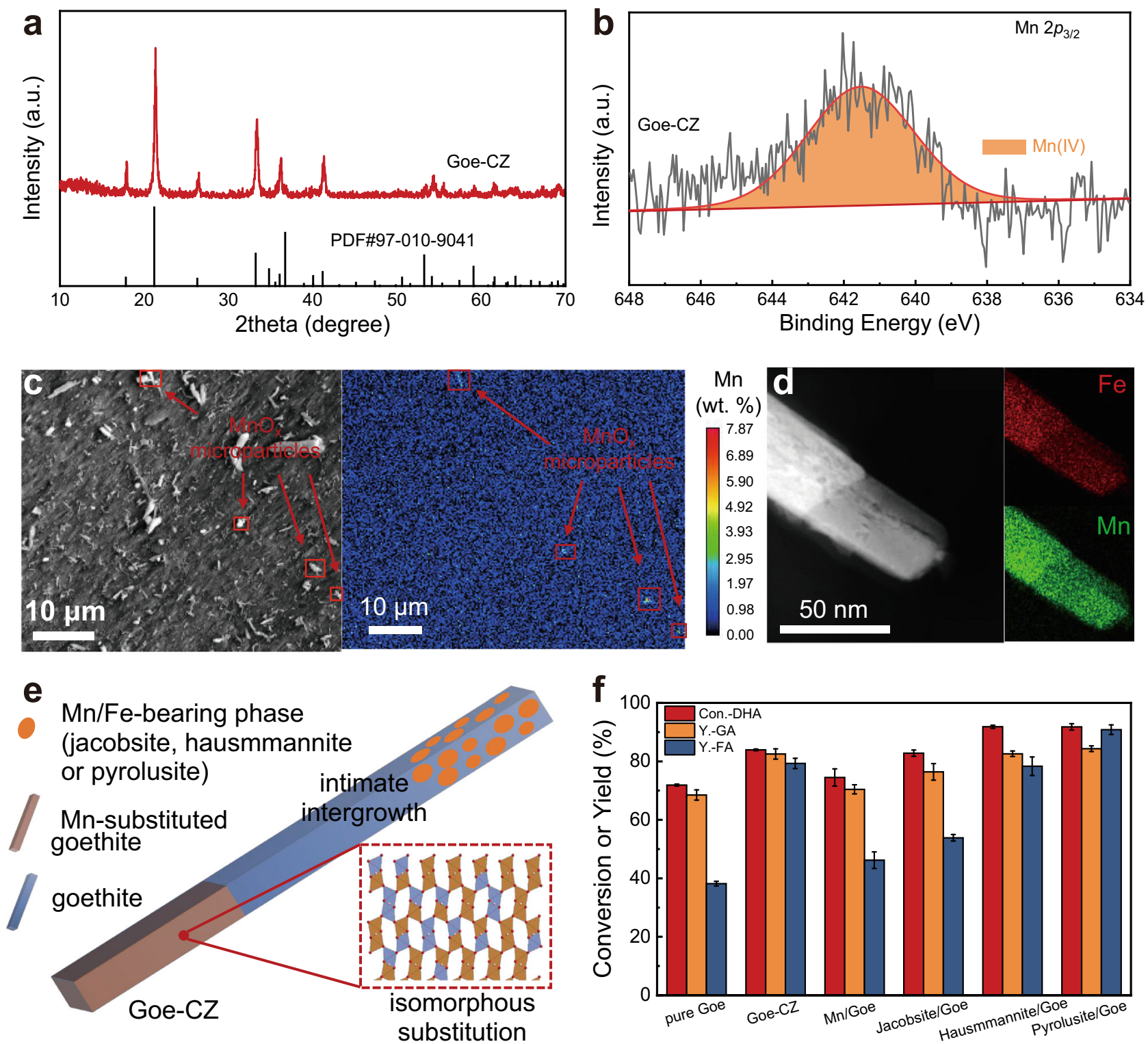

Fig. 2 Structural and morphological characterizations of Goe-CZ and catalytic performance of mimic catalysts. a XRD pattern. b Mn $2 p_{3 / 2} X P S$ spectra. c EPMA images (the spots with high $\mathrm{Mn}$ signal are proposed jacobsite $\left(\mathrm{MnFe}_{2} \mathrm{O}_{4}\right)$, hausmmannite $\left(\mathrm{Mn}_{3} \mathrm{O}_{4}\right)$, or pyrolusite $\left(\beta-\mathrm{MnO}_{2}\right)$ microparticles). d STEM-EDS-mapping (Fe: red, Mn: green). e Schematic illustration of different distribution forms of Mn on Goe-CZ. $\mathbf{f}$ Catalytic activity for DHA oxidation over the mimic $\mathrm{Mn} / \mathrm{Fe}$-bearing mineral-attached and $\mathrm{Mn}$-doped goethite catalysts. Reaction conditions: catalyst $30 \mu \mathrm{mol}, \mathrm{DHA} 1 \mathrm{mmol}, \mathrm{H}_{2} \mathrm{O}_{2} 0.2 \mathrm{~mL}$ (30 wt $\% \mathrm{H}_{2} \mathrm{O}_{2}$ aqueous), $25^{\circ} \mathrm{C}, 400 \mathrm{rpm}, 24 \mathrm{~h}$. Error bars represent standard deviations from triplicate experiments.

system from DHA to other biomass-based platform molecules classified as: lignocellulose-derived compounds (glucose and xylose), lignin-based model compounds ( $\beta-\mathrm{O}-4$ ketone: 2 phenoxyacetophenone), and glycerol-based compounds (glycerol and 1,2-propanediol). Compared to the pure goethite, the $\mathrm{MnO}_{2} /$ Goe catalyst showed improved conversion of the five substrates, especially for xylose, and achieved $16.39-37.78 \%$ enhancement in total carbon atom selectivity (Supplementary Fig. 13 and Supplementary Table 3). This result adequately demonstrates that this nature-inspired catalyst is effective not only for the selective oxidation of DHA but also for enhancing the $\mathrm{C}-\mathrm{C}$ cleavage and suppressing the excessive product oxidation for other biomass-based substrates.

Although the reaction formed strongly acidic products, the rod-like morphology of the goethite composition in the catalyst remained intact after the catalytic reaction (Supplementary
Fig. 14). During the reuse cycling experiments (Supplementary Table 4), the GA and FA yields decreased slightly from 83.2, 93.4 to $78.7 \%, 84.0 \%$ during the first cycle but remained nearly unchanged as the number of reuse cycles increased, indicating the satisfactory reusability of the $\mathrm{MnO}_{2} /$ Goe catalyst. The leached Fe was lower than $0.14 \%$ in all five cycles and the leached Mn was in the range of $1.08-1.91 \%$ in the last four cycles, not including the first cycle. In order to investigate the activity and durability of the catalyst for practical industrial applications, we further tested its catalytic performance using scaled-up continuous $(0.36 \mathrm{~mol}$ $\mathrm{DHA} /$ day) and batch (2.5 mol DHA, 2500-times scale-up) reactors. Within the 10 -day continuous operation, the catalytic activity stabilized after the first day with similar GA and FA selectivity and slightly decreased DHA conversion due to the dilution of $\mathrm{H}_{2} \mathrm{O}_{2}$ required for safe operation under scaled-up conditions (Fig. 3d and Supplementary Fig. 15). The 2500x 


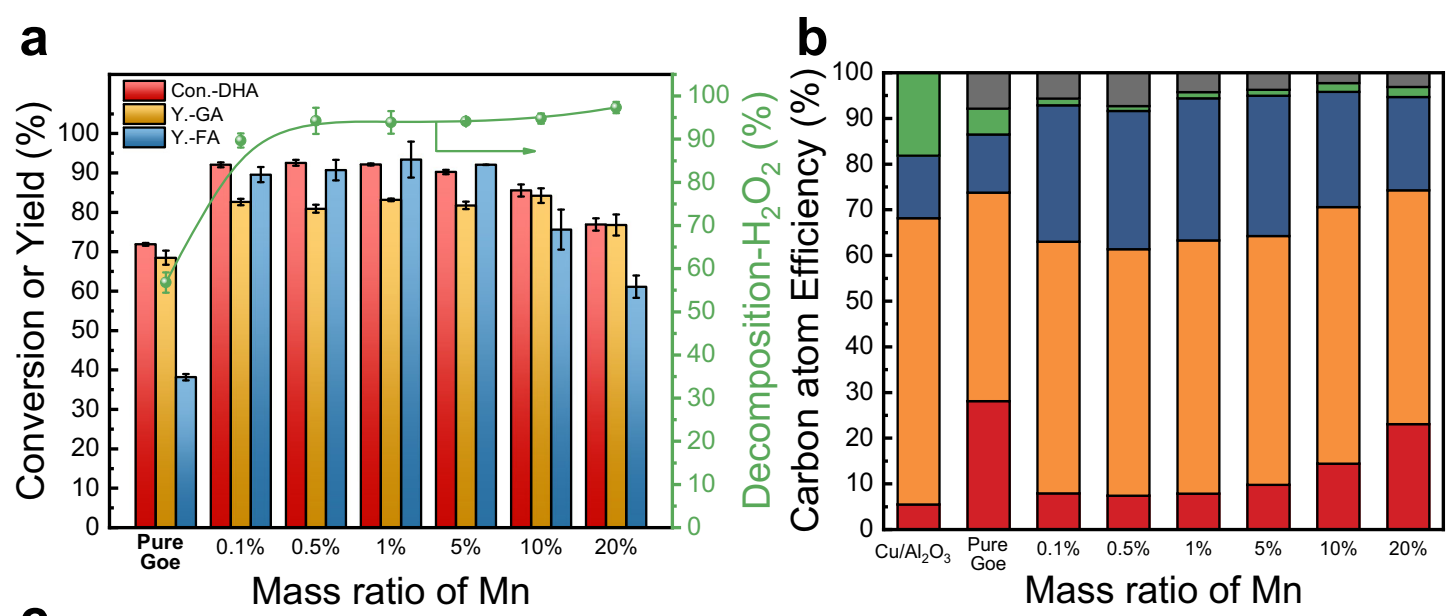

C
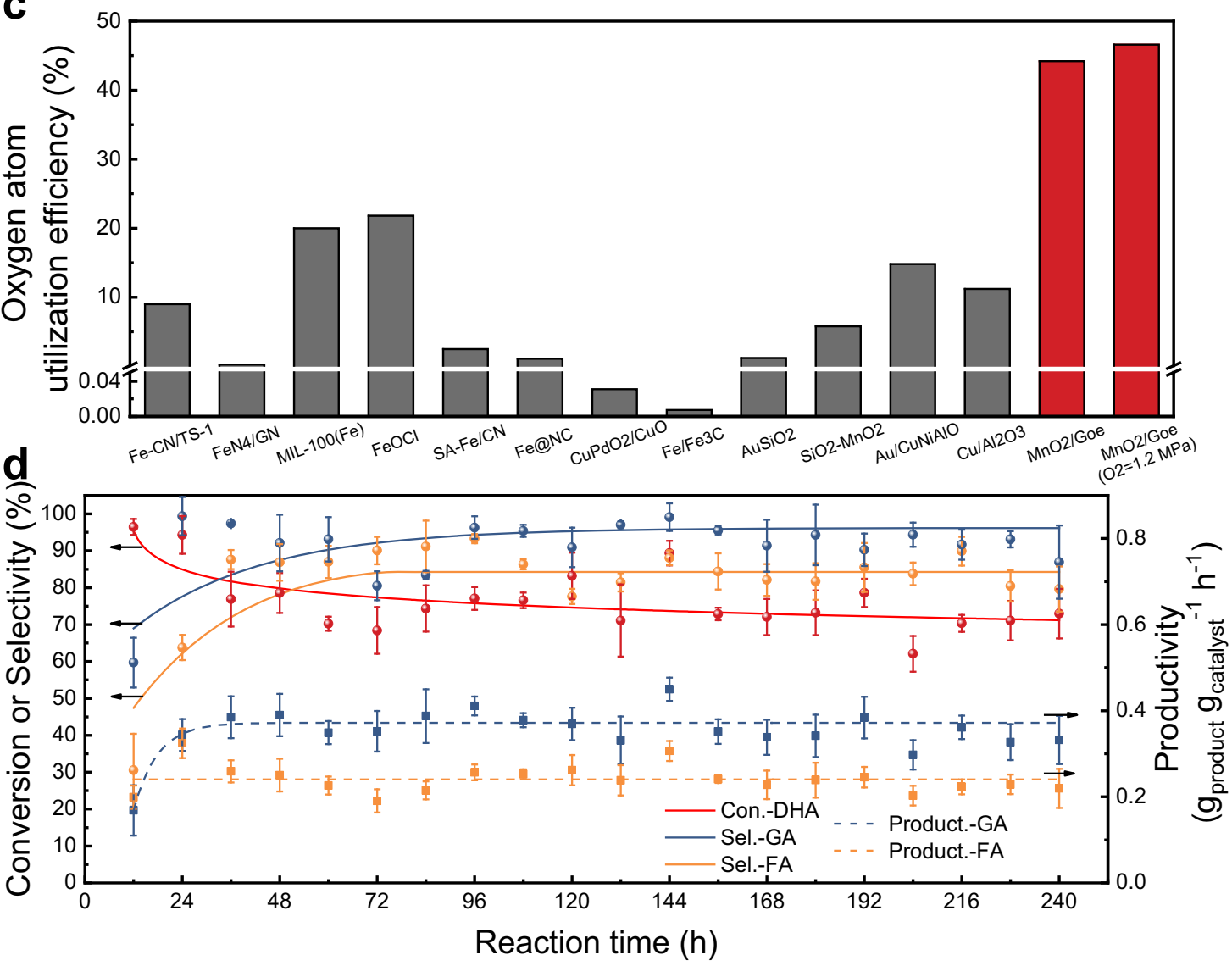

Fig. 3 Catalytic activity, atom efficiency, and continuous stability test. a, b Catalytic activity and carbon atom efficiency for DHA oxidation over $\mathrm{MnO}_{2} /$ Goe with different mass ratio of $\mathrm{Mn}$. Red: unreacted DHA; Orange: GA; Blue: FA; Green: $\mathrm{CO}_{2}$; Gray: unknown intermediates. c Comparison of oxygen atom utilization efficiency for the typical heterogeneous catalytic oxidation processes using $\mathrm{H}_{2} \mathrm{O}_{2}$ as oxidant. The detailed information of these systems was listed in Supplementary Table 2. d Catalytic performance of the $\mathrm{MnO}_{2} / \mathrm{Goe}$ catalyst under the continuous flow condition. Reaction conditions for DHA oxidation: catalyst $30 \mu \mathrm{mol}, \mathrm{DHA} 1 \mathrm{mmol}, \mathrm{H}_{2} \mathrm{O}_{2} 0.2 \mathrm{~mL}$ ( $30 \mathrm{wt} \% \mathrm{H}_{2} \mathrm{O}_{2}$ aqueous), $25^{\circ} \mathrm{C}, 400 \mathrm{rpm}, 24 \mathrm{~h}$ (batch experiment); catalyst $2 \mathrm{~g}, 1 \mathrm{mmol} \mathrm{DHA}$ in $2 \mathrm{mmol} \mathrm{H}_{2} \mathrm{O}_{2}$ aqueous solution (10 wt\%), $0.15 \mathrm{~mL} / \mathrm{min}, 25^{\circ} \mathrm{C}$ (scale-up continuous experiment). Error bars represent standard deviations from triplicate experiments.

scaled-up batch system could also achieve a similar performance as that of the small-sized reactor system (Supplementary Table 5). As shown in Supplementary Table 6, the productivity $\left(g_{\text {product }} g_{\text {catalyst }}^{-1} \mathrm{~h}^{-1}\right)$ of our scaled-up continuous and batch systems is much higher than that of the reported $\mathrm{Cu} / \mathrm{Al}_{2} \mathrm{O}_{3}$ system, even comparable with some of the glycerol-based systems requiring high temperatures. These results clearly highlight the promising potentials of this catalyst for industrial applications.
Understanding and improving the $\mathrm{C}-\mathrm{C}$ cleavage of DHA. Activation of $\mathrm{C}-\mathrm{C}$ bonds can be achieved in a variety of pathways including radical transfer, nucleophilic attack, and transition-metal insertion ${ }^{50-52}$. Since goethite can activate $\mathrm{H}_{2} \mathrm{O}_{2}$ to form radicals in a Fenton-like manner, we first used electron paramagnetic resonance (EPR) and the spin trap 5,5-Dimethyl-1pyrroline N-oxide (DMPO) to monitor the formation of radicals during DHA selective oxidation. Typical EPR signals belonging to DMPO-OH and DMPO-OOH adducts were clearly resolved, 

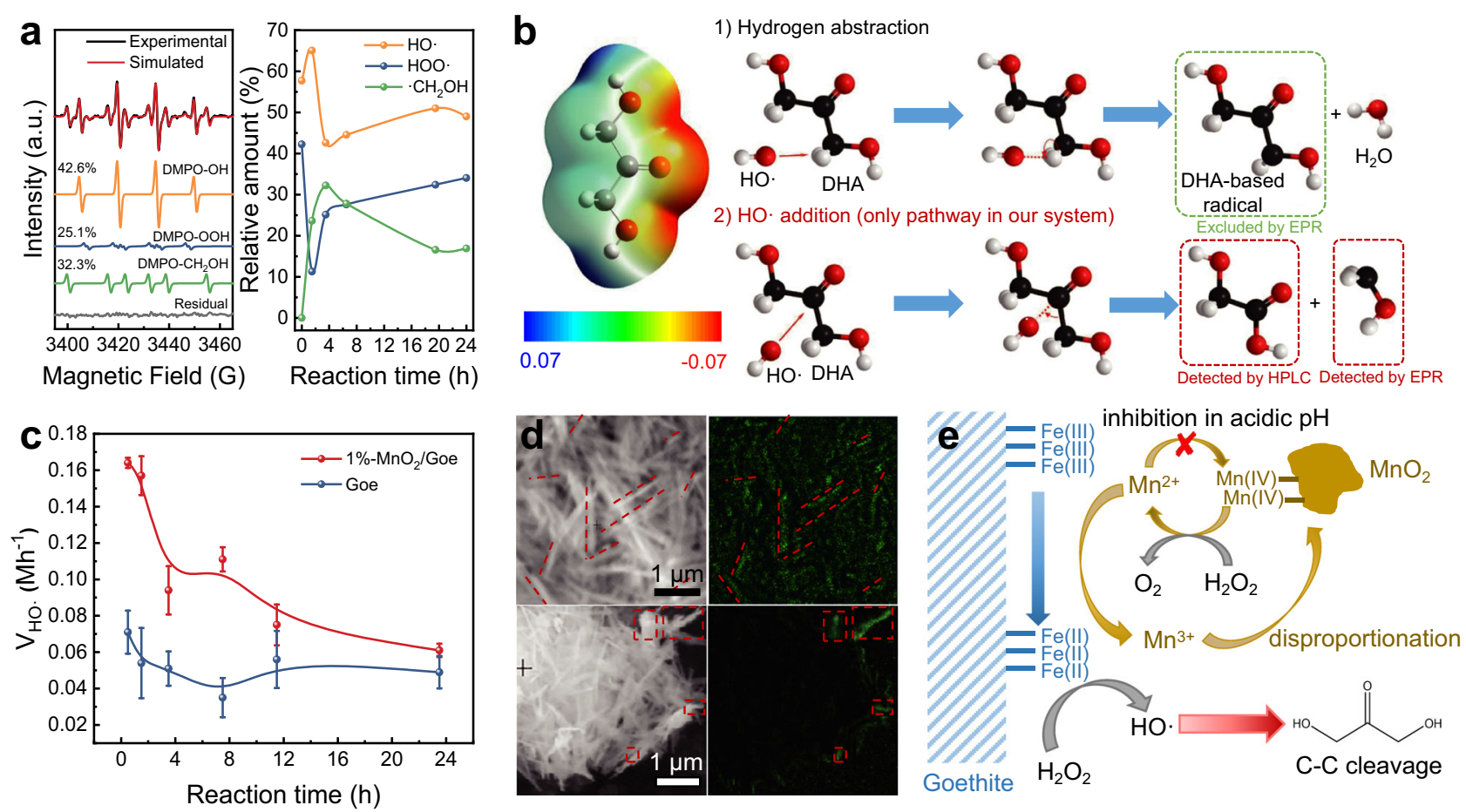

Fig. 4 C - C bond cleavage behavior of DHA molecule. a EPR signals of the DMPO adducts ( $3.5 \mathrm{~h}$ ) and relative amount of the DMPO-X adducts over time after adding $\mathrm{DHA}$ to the $1 \%-\mathrm{MnO}_{2} / \mathrm{Goe}$ system (Hfs parameters: $A_{N}=15.1, A_{H}=14.8 \mathrm{G}$ for $\cdot \mathrm{OH}, \mathrm{A}_{\mathrm{N}}=14.3, A_{B H}=11.4, A_{\gamma H}=1.2 \mathrm{G}$ for $\cdot 0 O H$, and $A_{N}=16.0, A_{H}=22.8 \mathrm{G}$ for $\cdot \mathrm{CH}_{2} \mathrm{OH}$ ). $\mathbf{b}$ Optimized structure and electrostatic potential distribution of DHA (the red surface corresponds to a negative region, whereas the blue surface corresponds to a positive region. Gray, red, and white spheres represent $\mathrm{C}, \mathrm{O}$, and $\mathrm{H}$, respectively) and possible reaction pathways for the attack of $\mathrm{HO}$. to DHA. c HO formation rate over time in pure Goe and $1 \%-\mathrm{MnO}_{2} /$ Goe systems. Error bars represent standard deviations

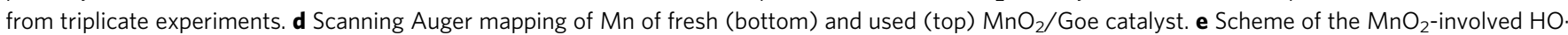
formation mechanism on goethite surface.

suggesting the formation of $\mathrm{HO}$. and HOO. radicals (Fig. 4a). According to the optimized structure and electrostatic potential distribution of DHA, the hydroxyl oxygen atoms are oriented towards ketyl oxygen atoms, which makes the DHA molecularly polarized and the attack of $\mathrm{HO}$. more favorable along the opposite direction of oxygen atoms (Fig. 4b). There are mainly two routes of reacting DHA with HO. radicals: (1) hydrogen abstraction of the $a$-carbon by a HO radical to form a DHAbased radical; (2) the addition of a $\mathrm{HO}$. radical to the carbonyl group to form a carbonyl-centered radical, which can be then decomposed into GA and a hydroxymethyl radical (Fig. 4b). Although the formation of GA and FA implied that the latter pathway dominated the DHA oxidation in our system, we probed the radical intermediates with the aid of EPR. In addition to DMPO-OH and DMPO-OOH adducts, a new signal with hyperfine splitting parameters of $\mathrm{A}_{\mathrm{N}}=15.9 \mathrm{G}$ and $\mathrm{A}_{\mathrm{H} \beta}=22.7 \mathrm{G}$ could be assigned to the DMPO-hydroxymethyl radical adduct (DMPO- $\mathrm{CH}_{2} \mathrm{OH}$ ), which indicated the DHA molecule was activated by the addition of $\mathrm{HO}$. to carbonyl group. There was no signal of any other radicals observed, completely ruling out the hydrogen abstraction pathway. The relative amount of fitted DMPO-. $\mathrm{CH}_{2} \mathrm{OH}$ adducts over time showed a negative correlation with that of DMPO-.OH, suggesting a cause-and-effect relationship between the two radicals (Fig. 4a). The DMPO-. $\mathrm{CH}_{2} \mathrm{OH}$ adduct increased rapidly at the early stage and reached a peak at $4 \mathrm{~h}(30 \%)$, indicating that the $\mathrm{C}-\mathrm{C}$ cleavage took place mainly in the early stages.

Moreover, the $1 \%-\mathrm{MnO}_{2} /$ Goe catalyst exhibited a $\mathrm{HO}$. generation rate of $0.164 \mathrm{M} \cdot \mathrm{h}^{-1}$ at the first hour, more than twice as high as that of goethite $\left(0.071 \mathrm{Mh}^{-1}\right)$ (Fig. 4c). This enhancement progressively decayed over time, which agrees with the early-stage $\mathrm{C}-\mathrm{C}$ cleavage processes. Unlike iron (hydro) oxides, $\mathrm{MnO}_{2}$ cannot activate $\mathrm{H}_{2} \mathrm{O}_{2}$ to generate $\mathrm{HO}$., but rather catalyzes the decomposition of $\mathrm{H}_{2} \mathrm{O}_{2}$ via a two-electron transfer to $\mathrm{O}_{2}$ (Eqs. 1-3) ${ }^{53}$. Therefore, the $\mathrm{HO}$. enhancement is likely caused by the $\mathrm{MnO}_{2}$ /Goe synergy. As we observed how leaching of $\mathrm{Mn}^{2+}$ and the acidic environment prohibited the cycling of reduced $\mathrm{Mn}^{2+}$ back to $\mathrm{MnO}_{2}$, we anticipated that the $\mathrm{Mn}^{2+}$ accumulation near the interface could potentially reduce the number of $\mathrm{Fe}$ (III) sites for promoting HO. generation due to the proximity of the two redox couples $\left(\mathrm{Mn}^{3+} / \mathrm{Mn}^{2+}=0.9-1.5 \mathrm{~V}\right.$, goethite/Fe(II) $=\sim 1.0 \mathrm{~V}$ at $\mathrm{pH}=1)(\text { Eq. } 4)^{54}$. Such $\mathrm{Mn}^{2+}$ effect was then surveyed by the pyrophosphate $\left(\mathrm{P}_{2} \mathrm{O}_{7}{ }^{4-}\right)$ complexing experiment. The presence of $\mathrm{P}_{2} \mathrm{O}_{7}{ }^{4-}$ ligand traps $\mathrm{Mn}^{2+}$ and prevents redox shuttling to goethite, which in turn greatly inhibits the conversion of DHA at $10 \mathrm{mM} \mathrm{P}_{2} \mathrm{O}_{7}{ }^{4-}$ (Supplementary Fig. 16a $)^{55,56}$. Consistently, when $\mathrm{Mn}^{2+}$ ions were directly added to the pure goethite system, an activity increase was also observed (Supplementary Fig. 16b). Such redox cycle effect was also supported by the higher fraction of $\mathrm{Fe}$ (II) in the Fe $2 p_{3 / 2}$ XPS for $\mathrm{MnO}_{2} /$ Goe (Supplementary Fig. 16c and Supplementary Table 7).

During the $\mathrm{Mn}^{2+}$-promoted reduction of $\mathrm{Fe}(\mathrm{III})$, the generated $\mathrm{Mn}^{3+}$ returns to $\mathrm{MnO}_{2}$ via rapid disproportionation under the strongly acidic environment (Eq. 5) 57 , which was further verified by Auger mapping. As shown in Fig. 4e, Mn signals appeared on the surface of goethite and were distributed along the rod-like structure after the reaction compared to the fresh $\mathrm{MnO}_{2} /$ Goe catalyst, which indicates that the $\mathrm{Mn}^{2+}$ oxidation and the following $\mathrm{Mn}^{3+}$ disproportionation had occurred on the goethite surface, forming $\mathrm{MnO}_{2}$ particles via Eqs. 4, $5^{55}$. Based on these results, we proposed the mechanism for the $\mathrm{HO}$. generation catalyzed by the $\mathrm{MnO}_{2} /$ Goe catalyst (Fig. 4f). The reductively 

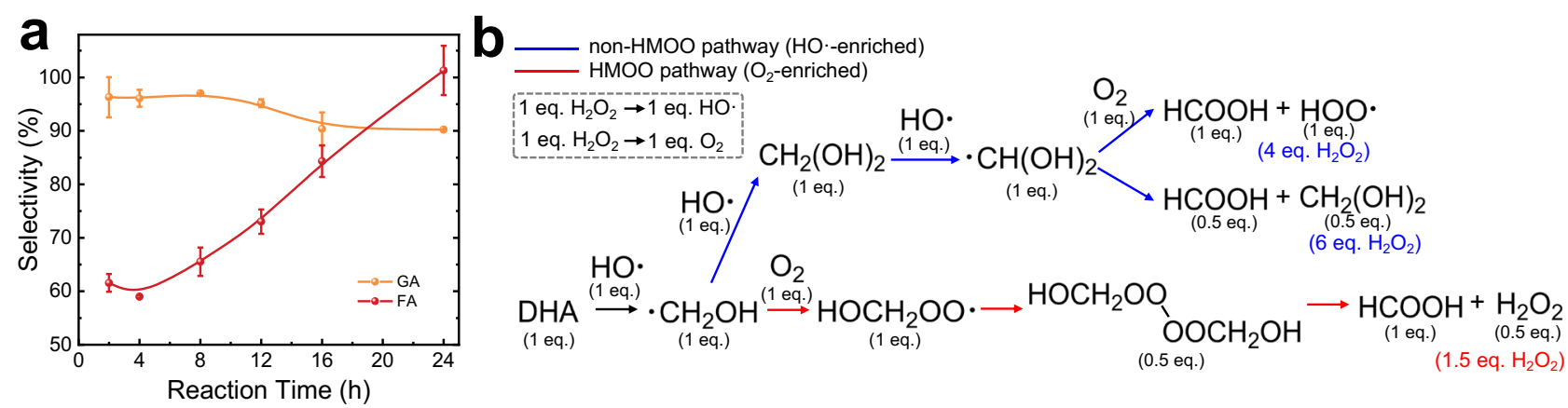

Fig. 5 Products selectivity and reaction pathways analysis. a Selectivity profile over $\mathrm{MnO}_{2} / \mathrm{Goe}-1 \%$ catalyst as a function of time (the change in the concentrations of DHA, GA, and FA was shown in Supplementary Fig. 16). Error bars represent standard deviations from triplicate experiments. $\mathbf{b}$ Stoichiometric analysis of $\mathrm{H}_{2} \mathrm{O}_{2}$ required to produce 1 molar equivalent $\mathrm{FA}$ based on the different pathways.

released $\mathrm{Mn}^{2+}$ reacts with $\mathrm{Fe}(\mathrm{III})$ sites on the goethite surface to form $\mathrm{Fe}(\mathrm{II})$ sites. The formed $\mathrm{Fe}(\mathrm{II})$ sites can active $\mathrm{H}_{2} \mathrm{O}_{2}$ via a single-electron transfer pathway to produce $\mathrm{HO}$. that cleave the $\mathrm{C}-\mathrm{C}$ bonds of DHA (Eq. 6). Simultaneously, $\mathrm{Mn}^{2+}$ is oxidized to $\mathrm{Mn}^{3+}$ and then disproportionates back into $\mathrm{MnO}_{2}$ to recycle the catalyst.

$$
\begin{gathered}
\mathrm{MnO}_{2}+\mathrm{H}_{2} \mathrm{O}_{2}+2 \mathrm{H}^{+} \rightarrow \mathrm{Mn}^{2+}+2 \mathrm{H}_{2} \mathrm{O}+\mathrm{O}_{2} \\
\mathrm{Mn}^{2+}+2 \mathrm{H}_{2} \mathrm{O}_{2} \rightarrow \mathrm{Mn}(\mathrm{OH})_{2}+\mathrm{O}_{2}+2 \mathrm{H}^{+} \\
\mathrm{Mn}(\mathrm{OH})_{2}+\mathrm{H}_{2} \mathrm{O}_{2} \rightarrow \mathrm{MnO}_{2}+2 \mathrm{H}_{2} \mathrm{O} \\
\equiv \mathrm{Fe}(\mathrm{III})+\mathrm{Mn}^{2+} \rightarrow \equiv \mathrm{Fe}(\mathrm{II})+\mathrm{Mn}^{3+} \\
2 \mathrm{Mn}^{3+}+2 \mathrm{H}_{2} \mathrm{O} \rightarrow \mathrm{MnO}_{2}+\mathrm{Mn}^{2+}+4 \mathrm{H}^{+} \\
\equiv \mathrm{Fe}(\mathrm{II})+\mathrm{H}_{2} \mathrm{O}_{2}+\mathrm{H}^{+} \rightarrow \equiv \mathrm{Fe}(\mathrm{III})+\mathrm{HO} \cdot+\mathrm{H}_{2} \mathrm{O}
\end{gathered}
$$

Regulating the $\cdot \mathrm{CH}_{2} \mathrm{OH}$ transformation to $\mathrm{FA}$. To explore the chain propagation induced by the $\mathrm{C}-\mathrm{C}$ cleavage, we first investigated the kinetics of GA and FA formation on the $\mathrm{MnO}_{2}$ /Goe catalyst (Fig. 5a). The selectivity of GA remained essentially unchanged and only slightly decreased after $12 \mathrm{~h}$ due to the possible consecutive oxidation of GA. Notably, the selectivity of FA was relatively low at the early stage but exhibited an unusual trend of higher selectivity under longer reaction time. These results are consistent with the evolution of $\cdot \mathrm{CH}_{2} \mathrm{OH}$ species (Eq. 7), impelling us to investigate their reaction pathway.

$$
\mathrm{CH}_{2} \mathrm{OHCOCH}{ }_{2} \mathrm{OH}+\mathrm{HO} \rightarrow \mathrm{CH}_{2} \mathrm{OHCOOH}+\cdot \mathrm{CH}_{2} \mathrm{OH}
$$

As a radical, $\cdot \mathrm{CH}_{2} \mathrm{OH}$ can inevitably self-couple to form ethylene glycol. In our system, only traces of ethylene glycol were detected with very small production values $(<0.1 \%$ DHA conversion) (Supplementary Fig. 18), indicating that the selfcoupling of $\cdot \mathrm{CH}_{2} \mathrm{OH}$ radicals is not kinetically dominant. Alternatively, in the HO--enriched Fenton system, $\cdot \mathrm{CH}_{2} \mathrm{OH}$ radicals can first combine with $\mathrm{HO}$. to form hydrated formaldehyde $\left(\mathrm{CH}_{2}(\mathrm{OH})_{2}\right)$ (Eq. 8) and then be oxidized to . $\mathrm{CH}(\mathrm{OH})_{2}$ radicals and FA (Eqs. 9-11) ${ }^{58}$. The schematic diagram based on elementary reactions provided a clear stoichiometric analysis (Fig. 5b), which turned out that converting 1 mole of $\mathrm{DHA}$ to FA via the HO--enriched pathway requires 4 or 6 equivalents of $\mathrm{H}_{2} \mathrm{O}_{2}$. However, in our system, only 2 equivalents of $\mathrm{H}_{2} \mathrm{O}_{2}$ were added, indicating that other species rather than $\mathrm{HO}$. should act as the oxidant of $\cdot \mathrm{CH}_{2} \mathrm{OH}$ radicals. In addition to $\mathrm{HO} \cdot \mathrm{O}_{2}$ generated through $\mathrm{H}_{2} \mathrm{O}_{2}$ decomposition (Eq. 5) may also react with $\cdot \mathrm{CH}_{2} \mathrm{OH}$ radicals as another oxygen source.
Hydroxymethyl peroxy radicals $\left(\cdot \mathrm{OOCH}_{2} \mathrm{OH}, \mathrm{HMOO}\right)$ can be generated under oxygen-rich environment (Eq. 12) and can subsequently undergo decomposition to form FA (Eq. 13) $)^{59,60}$. The stoichiometric analysis of this process in Fig. 5b suggests that the conversion of 1 mole of DHA to FA only requires 1.5 molar equivalents of $\mathrm{H}_{2} \mathrm{O}_{2}$, much lower than that of the non-HMOO pathway.

$$
\begin{gathered}
\cdot \mathrm{CH}_{2} \mathrm{OH}+\mathrm{HO} \cdot \rightarrow \mathrm{CH}_{2}(\mathrm{OH})_{2} \\
\mathrm{CH}_{2}(\mathrm{OH})_{2}+\mathrm{HO} \rightarrow \cdot \mathrm{CH}(\mathrm{OH})_{2}+\mathrm{H}_{2} \mathrm{O} \\
\cdot \mathrm{CH}(\mathrm{OH})_{2}+\mathrm{O}_{2} \rightarrow \mathrm{CHOOH}+\mathrm{HOO} \\
2 \cdot \mathrm{CH}(\mathrm{OH})_{2} \rightarrow \mathrm{CHOOH}+\mathrm{CH}_{2}(\mathrm{OH})_{2} \\
\cdot \mathrm{CH}_{2} \mathrm{OH}+\mathrm{O}_{2} \rightarrow \mathrm{HOCH}_{2} \mathrm{OO} \\
2 \mathrm{HOCH}_{2} \mathrm{OO} \cdot \rightarrow\left[\mathrm{HOCH}_{2} \mathrm{OO}-\mathrm{OOCH}_{2} \mathrm{OH}\right] \rightarrow 2 \mathrm{CHOOH}+\mathrm{H}_{2} \mathrm{O}_{2}
\end{gathered}
$$

Due to the catalase-like activity of $\mathrm{MnO}_{2}$, we discovered that the dissolved oxygen concentration was significantly higher in our $\mathrm{MnO}_{2} /$ Goe system than in the pure Goe system (Supplementary Fig. 19), especially in the first few hours (31.8 ppm vs. $11.0 \mathrm{ppm}$ ). When we continuously bubbled $\mathrm{N}_{2}$ to remove dissolved oxygen during the reaction, the FA yield remarkably decreased (Fig. 6a), while the DHA conversion and GA yield were only slightly inhibited. Correspondingly, for the pure goethite system under $\mathrm{O}_{2}$ pressure, the FA yield increased significantly with increasing $\mathrm{O}_{2}$ pressure (Supplementary Fig. 20). These results suggested that $\mathrm{O}_{2}$ greatly contributed to the FA production as a reactant, implying the dominance of the $\mathrm{HMOO}$ path during $\cdot \mathrm{CH}_{2} \mathrm{OH}$ conversion. Since the presence of various radicals in the system hindered the identification of HMOO radicals, we designed ${ }^{18} \mathrm{O}_{2}$ isotope experiments to validate their presence in our $\mathrm{MnO}_{2} / \mathrm{Goe}$ system. Once ${ }^{18} \mathrm{O}_{2}$ molecules react with $\cdot \mathrm{CH}_{2} \mathrm{OH}$ radicals, ${ }^{18} \mathrm{O}$-labeled FA $\left(\mathrm{HC}^{18} \mathrm{OOH}, \quad m / z=47\right)$ should be generated, while only $\mathrm{HC}^{16} \mathrm{O}_{2} \mathrm{H}(\mathrm{m} / z=45)$ should be generated otherwise (Supplementary Fig. 21). As shown in Fig. 6b, the relative abundance of detected ${ }^{18} \mathrm{O}$-labeled FA and its fragments is enhanced by bubbling ${ }^{18} \mathrm{O}_{2}$ into the reaction solution, confirming the existence of HMOO and its contribution to FA formation. These results indicate that the HMOO pathway provides an easily-accessed route to fix and utilize the $\mathrm{O}_{2}$ without involving the difficult $\mathrm{O}-\mathrm{O}$ activation by spin inversion ${ }^{61}$.

Unlike short-lived HO. radicals $\left(t_{1 / 2}=10^{-9} \mathrm{~s}\right)$, HMOO radicals have longer life-time $\left(t_{1 / 2}=7 \times 10^{-5} \mathrm{~s}\right)$ and tend to self-couple or couple with $\mathrm{HOO}$ to form stable intermediates at low $\mathrm{pHs}^{60,62}$. As shown in Fig. 6c, Operando ATR-IR spectra provided insight 

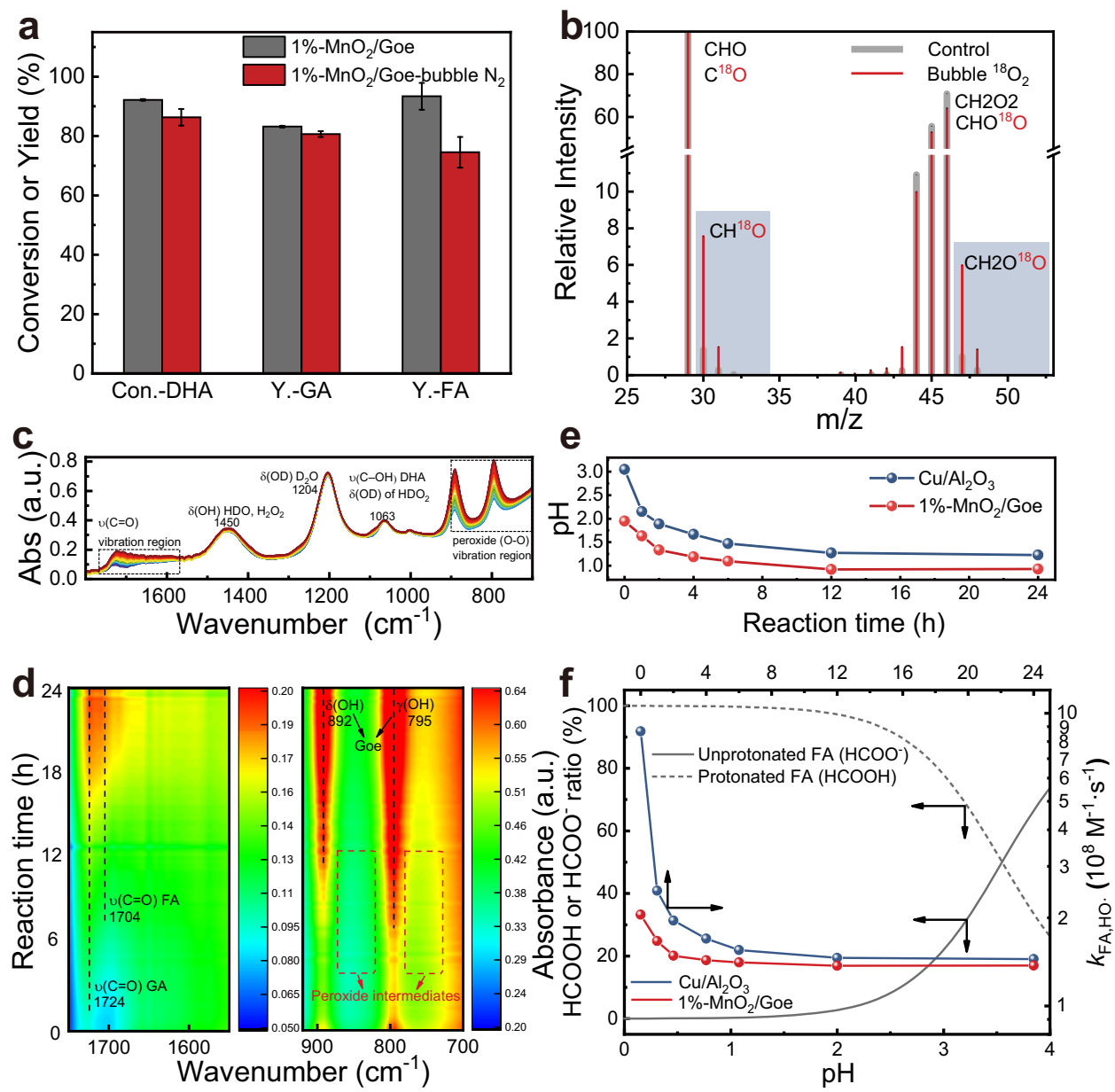

Fig. 6 FA formation investigations. a Effect of bubbling $\mathrm{N}_{2}$ on the activity of $\mathrm{MnO}_{2} /$ Goe catalyst. Error bars represent standard deviations from triplicate experiments. b MS signals of FA and its fragments during conversion of DHA with/without bubbling ${ }^{18} \mathrm{O}_{2}$. c, d Operando ATR-FTIR spectra during conversion of $\mathrm{DHA}$ in $\mathrm{D}_{2} \mathrm{O}$ and the corresponding carbonyl bond and organic peroxide bond vibration regions. e, $\mathbf{f} V$ ariation in $\mathrm{pH}$ during the reaction process using $1 \%-\mathrm{MnO}_{2} / \mathrm{Goe}$ and $\mathrm{Cu} / \mathrm{Al}_{2} \mathrm{O}_{3}$ catalysts and the corresponding protonated/unprotonated $\mathrm{FA}$ ratio with the change of $\mathrm{pH}$ value and the calculated average intrinsic rate constants of FA with $\mathrm{HO}$. The calculation of the ratio and average intrinsic rate constants were described in $\mathrm{SI}$. The preparation and reaction conditions of $\mathrm{Cu} / \mathrm{Al}_{2} \mathrm{O}_{3}$ were the same as that in the literature ${ }^{13}$.

into the generation and decomposition of products and intermediates of the DHA oxidation, particularly for $\cdot \mathrm{CH}_{2} \mathrm{OH}$ conversion. The bands at 1724 and $1704 \mathrm{~cm}^{-1}$ are assigned to the $v(\mathrm{C}=\mathrm{O})$ vibration of GA and FA (Fig. $6 \mathrm{~d})^{13}$, and the evolution of the FA vibration band significantly lagged behind that of GA. Although the organic peroxidic vibration region $\left(700-900 \mathrm{~cm}^{-1}\right)$ was more disturbed by the $\mathrm{O}-\mathrm{H}$ vibration of goethite, two weak bands at $\sim 750$ and $\sim 850 \mathrm{~cm}^{-1}$ could still be observed during $4 \mathrm{~h}$ to $12 \mathrm{~h}$, demonstrating the presence of peroxidic intermediates at this stage $e^{63}$. Correspondingly, it was found that about $30 \%$ of $\mathrm{C} 1$ products (FA, formaldehyde and hydrated formaldehyde) were lost during the first $2 \mathrm{~h}$ in our $\mathrm{MnO}_{2}$ /Goe system. While this amount gradually decreased to close to zero after $12 \mathrm{~h}$ (Supplementary Fig. 22), the loss of unknown products might be attributed to the coupling intermediates of HMOO.

We further compared the kinetics of the HMOO and nonHMOO pathways (Supplementary Table 8). The persistent HMOO radicals and their coupling peroxidic intermediates confirmed the domination of the $\mathrm{O}_{2}$-rich step described in Eq.12, which reflects the slower kinetics of the HMOO pathway than that of the non-HMOO pathway. The slow transformation of $\cdot \mathrm{CH}_{2} \mathrm{OH}$ radicals to $\mathrm{FA}$ in the $\mathrm{MnO}_{2} /$ Goe system bypasses the early-stage Fenton-like activity to avoid the excessive oxidation of FA. In addition, due to the continuous accumulation of FA, the
$\mathrm{pH}$ of our $\mathrm{MnO}_{2} /$ Goe system was maintained at a low range $(0.9-1.6)$ throughout the reaction compared to that of the $\mathrm{Cu} /$ $\mathrm{Al}_{2} \mathrm{O}_{3}$ system $(1.3-2.2)$ with low FA yield (Fig. 6e). The $\mathrm{pH}$ of the systems significantly affected the degree of protonation/deprotonation of FA, which changed the intrinsic rate constant of $\mathrm{HO}$. with FA $\left(k_{\mathrm{HCO}_{2}^{-}, \mathrm{HO}}=3.2 \times 10^{9} \mathrm{M}^{-1} \mathrm{~s}^{-1}\right.$ vs. $k_{\mathrm{HCO}_{2} \mathrm{H}, \mathrm{HO}}=1.3 \times$ $\left.10^{8} \mathrm{M}^{-1} \mathrm{~s}^{-1}\right)^{64}$. We calculated the ratio of protonated/deprotonated FA in the two systems and further determined the average intrinsic rate. The reaction rate in our $\mathrm{MnO}_{2} / \mathrm{Goe}$ system was always lower than that in the $\mathrm{Cu} / \mathrm{Al}_{2} \mathrm{O}_{3}$ system; specifically, it was lower than one-fourth $\left(2.0 \times 10^{8} \mathrm{M}^{-1} \mathrm{~s}^{-1}\right.$ vs. $\left.8.7 \times 10^{8} \mathrm{M}^{-1} \mathrm{~s}^{-1}\right)$ in the early stage, which-in turn-greatly inhibited FA degradation (Fig. 6f). Based on these, a schematic comparison of the non-HMOO/HMOO pathways is shown in Fig. 7. Although the formed FA is inevitably degraded by HO. attack, the process is kinetically determined by two factors: the $\mathrm{HO}$. concentration and the intrinsic rate constant of $\mathrm{HO}$. with $\mathrm{FA}$ (Eq. 14). FA was rapidly generated but deeply oxidized in the early stage of the reaction under $\mathrm{HO}$--enriched environment. In contrast, the transformation of $\cdot \mathrm{CH}_{2} \mathrm{OH}$ to FA mediated by $\mathrm{HMOO}$ is a slow process, and, at low $\mathrm{pH}$, is accompanied by the gradual release of FA to reduce the average intrinsic rate for FA oxidation. Consequently, this all together inhibits the FA 


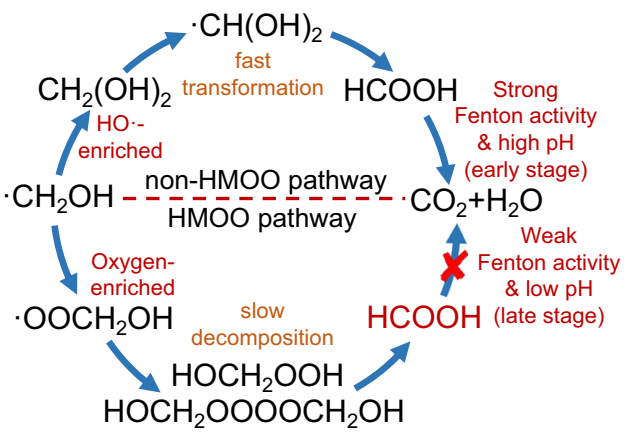

Fig. 7 Schematic illustration of the pathway regulation. Scheme of the proposed $\mathrm{HMOO}$ and non- $\mathrm{HMOO}$ pathways for $\cdot \mathrm{CH}_{2} \mathrm{OH}$ transformation.

degradation kinetics and regulates the $\mathrm{CH}_{2} \mathrm{OH}$ transformation toward high FA selectivity.

$$
-\frac{\mathrm{d}[\mathrm{FA}]}{\mathrm{d} t}=k_{\mathrm{ins}} \times[\mathrm{HO} \cdot] \times[\mathrm{FA}]
$$

\section{Discussion}

Heterogeneous Fenton chemistry has shown increasing promise in industrial oxidation processes targeting high selectivity. However, one of the major obstacles for Fenton-based chemicals production is inefficient $\mathrm{HO}$. generation. Inspired by natural goethite, we have successfully developed mimic $\mathrm{MnO}_{2} /$ Goe catalyst via simple mechanical mixing for the co-production of GA and FA from DHA. The reactions proceed efficiently and selectively under room temperature and atmospheric pressure, with high carbon atom efficiency and high $\mathrm{H}_{2} \mathrm{O}_{2}$ utilization. EPR studied $\mathrm{HO}$. generation kinetic and AEM images indicated that the incorporation of separate $\beta-\mathrm{MnO}_{2}$ phase can readily induce the acceleration of the $\mathrm{Fe}(\mathrm{III}) / \mathrm{Fe}$ (II) cycle on goethite surface to activate $\mathrm{H}_{2} \mathrm{O}_{2}$, which provides a tractable strategy for promoting Fenton-like activity without relying on sophisticated regulation in $\mathrm{Fe}$ active sites at the atomic level.

Understanding and regulating the evolution intermediates and radical is a more demanding challenge, which has rarely been achieved in heterogeneous catalysis. In this contribution, the stoichiometric analysis and kinetic experiments supported the switch of elemental steps towards FA formation with high $\mathrm{H}_{2} \mathrm{O}_{2}$ utilization efficiency, implying the contribution of the released $\mathrm{O}_{2}$ catalyzed by $\mathrm{MnO}_{2}$. Further, ${ }^{18} \mathrm{O}$ isotopic labeling experiments and operando IR measurements confirmed the presence of hydroxymethyl peroxide (HMOO) radical that is an important indicator species for the proposed pathway and formed under $\mathrm{O}_{2^{-}}$ rich environment. These characterization and mechanistic studies depict an overall scenario of the $\mathrm{C}-\mathrm{C}$ cleavage of DHA and the conversion from generated $\mathrm{CH}_{2} \mathrm{OH}$ radicals to $\mathrm{FA}$, which demonstrates that - at least for HO--dominated $\mathrm{C}-\mathrm{C}$ cleavage$\mathrm{O}_{2}$ can directly react with radical intermediates as a key oxygen donor to change the resulting product distribution.

In summary, this work not only develops a $\mathrm{MnO}_{2} /$ Goe catalyst that can selectively oxidize DHA to co-produce GA/FA in excellent carbon/oxygen efficiency, but also provides a typical example of how to control the radical pathway during $\mathrm{C}-\mathrm{C}$ cleavage. This system exhibits general feasibility for other biomass-based platforms although the detailed reaction mechanism needs to be elucidated, which highlights the great potential of Fenton chemistry as a powerful tool for the C-C cleavage and reveals an alternative route for the synthesis of various fine chemicals. It can also serve as a starting point for further studies on the interfacial reaction mechanism of radicalmediated $\mathrm{C}-\mathrm{C}$ activation.

\begin{abstract}
Methods
Chemicals and reagents. $\mathrm{Fe}\left(\mathrm{NO}_{3}\right)_{3} \cdot 9 \mathrm{H}_{2} \mathrm{O}, \mathrm{Mn}\left(\mathrm{NO}_{3}\right)_{2}$, sodium bicarbonate $\left(\mathrm{NaHCO}_{3}\right)$, and $\mathrm{NaOH}$ were purchased from Aladdin Chemical Inc. (Shanghai, China). DHA, GA, FA, and $30 \mathrm{wt} \% \mathrm{H}_{2} \mathrm{O}_{2}$ were obtained from Shanghai Titan Scientific Co., Ltd. (Shanghai, China). ${ }^{18} \mathrm{O}_{2}$ (97 atom\%) was purchased from Beijing InnoChem Scientific Co., Ltd. (Beijing, China). DMPO was purchased from Tokyo Chemical Industry Co., Ltd. (Tokyo, Japan). The chemicals used to synthesize goethite $(\alpha-\mathrm{FeOOH})$ are ACS grade and other chemicals are analytical grade. All chemicals were used without further purification. Milli-Q water was used throughout this study.
\end{abstract}

Iron and manganese-containing minerals. Goethite, hematite $\left(\alpha-\mathrm{Fe}_{2} \mathrm{O}_{3}\right)$, magnetite $\left(\mathrm{Fe}_{3} \mathrm{O}_{4}\right)$ were purchased from Sigma-Aldrich (St. Louis, MO, USA). Lepidocrocite $(\gamma-\mathrm{FeOOH})$ was purchased from Alfa-Aesar (Haverhill, MA, USA). Hausmannite $\left(\mathrm{Mn}_{3} \mathrm{O}_{4}\right)$ and pyrolusite $\left(\beta-\mathrm{MnO}_{2}\right)$ were purchased from Shanghai Macklin Biochemical Co., Ltd. (Shanghai, China). Microrods, nanorods, Mn-doped goethite, and jacobsite $\left(\mathrm{MnFe}_{2} \mathrm{O}_{4}\right)$ were synthesized according to procedures previously described (Supplementary Methods) ${ }^{65-68}$. Pyrite used in the study was obtained by directly mining from the commercial pyrite deposits located in Lincang County, Yunnan Province, China. Mn-rich mineral used in the study was obtained by directly mining from the commercial Mn oxides deposits located in Shijiazhuang City, Hebei Province, China, and has been identified as consisting of $\mathrm{SiO}_{2}$ and three Mn-containing phases (Todorokite, Groutite, and Birneesite) (Supplementary Fig. 23), but also contains a small amount of Fe (7.4 wt\%). Two natural goethite minerals used in the study were obtained by directly mining from the commercial massive sulfide lead-zinc deposits located in Chenzhou (CZ) County, Hunan Province, China, and Wenshan (WS) County, Yunnan Province, China, were labeled as Goe-CZ and Goe-WS, respectively, in which they were both formed in the unsaturated oxidation zone of the deposits as the secondary minerals. $\mathrm{MnO}_{x}$-attached goethite was prepared by mechanical mixing using a tube roller mixer (MSK-MIX-T8, HF-Kejing, China) under the scroll mode (30 rpm) for $1 \mathrm{~h}$. The commercially available goethite $(30-50 \mathrm{mesh})$, natural goethite $(>10 \mathrm{~cm})$, and natural pyrite $(1-5 \mathrm{~cm})$ were grinded and sieved manually to above 200 mesh for the activity test, while other catalyst powders ( $>200$ mesh) were directly used in the reaction. The structural information of all Fe/Mn-containing minerals is listed in Supplementary Table 9.

Characterization methods. The morphology of the catalyst was characterized by scanning electron microscopy (SEM, ZEISS GeminiSEM 500, German). The manganese distribution in natural goethite was identified using electron probe micro analyzer (EPMA, JEOL JXA-8530F, Japan) and transmission electron microscope (TEM, Thermo Scientific Talos F200X, USA) equipped with high angle annular dark field (HAADF) and energy dispersive X-ray (EDX) analysis detectors. $\mathrm{X}$-ray diffraction (XRD) patterns were collected on a Bruker D8 advance X-ray diffractometer (Bruker, USA) with a $\mathrm{Cu} \mathrm{Ka}$ radiation (=1.5406 $\AA$ ). The BET surface area was measured by $\mathrm{N}_{2}$ adsorption isotherms at $77 \mathrm{~K}$ using ASAP 2020 automated surface area analyzer (Micromeritics, USA). X-ray photoelectron spectroscopy (XPS) was collected on an ESCALAB 250Xi spectrometer (Thermo Scientific, USA) with a monochromatic Al Ka source (1486.6 eV, passing energy $20 \mathrm{eV}$ ), and all binding energies were calibrated with the $\mathrm{C} 1 \mathrm{~s}$ peak at $284.8 \mathrm{eV}$. Scanning Auger mapping (SAM) analysis was carried out using a PHI-710 Auger spectrometer (Physical Electronics, Inc., USA). Operando infrared absorption spectroscopy in the attenuated total reflection mode (ATR-IR) was collected on a ReactIR15 IR spectrometer (Mettler Toledo, USA). The formation of free radicals was examined by electron paramagnetic resonance spectroscopy (EPR, Bruker ELEXSYS 500-10/12, USA) using DMPO as a spin trap agent. The detailed ATR-IR measurements and DMPO-trapping procedures are described in Supplementary Methods.

Computational methods. All computational procedure was carried out using Gaussian 09 and Gaussian view 6.0 programs ${ }^{69}$. The optimization structure and electrostatic potential calculation of DHA have been performed using the B3LYP functional and the $6-31 \mathrm{~g}^{*}$ basis set.

Selective C-C bond cleavage of DHA. The selective $\mathrm{C}-\mathrm{C}$ bond cleavage of DHA was studied by batch experiments. In a typical experiment, $30.0 \mu \mathrm{mol}$ iron (hydr) oxide, $1.0 \mathrm{mmol} \mathrm{DHA}$, and $2 \mathrm{mmol} \mathrm{H}_{2} \mathrm{O}_{2}$ (30 wt $\% \mathrm{H}_{2} \mathrm{O}_{2}$ aqueous solution) were added to a $5 \mathrm{~mL}$ glass reactor and reacted under a stirring speed of $400 \mathrm{rpm}$ at $25^{\circ} \mathrm{C}$ for $24 \mathrm{~h}$. For the $\mathrm{N}_{2} /{ }^{18} \mathrm{O}_{2}$ bubbling experiment, the glass reactor was replaced with a modified HPLC sample vial containing a micro insert tube $(300 \mu \mathrm{L})$ to reduce the FA loss and total evaporation loss. At a set time interval, the suspension sample was withdrawn and immediately filtered $(0.22 \mu \mathrm{m}$ PES) to remove the solids. The concentrations of DHA, GA, and FA were analyzed using a highperformance liquid chromatography (HPLC, Waters 2695, USA) equipped with a diode array detector (DAD, Waters 2996, USA). The total concentrations of formaldehyde and hydrated formaldehyde (methanediol) were analyzed by HPLC after 2,4-dinitrophenylhydrazine (2,4-DNPH) derivatization ${ }^{70} \cdot \mathrm{H}_{2} \mathrm{O}_{2}$ concentration was analyzed spectrophotometrically using the titanium sulfate method ${ }^{71}$. The amount of generated $\mathrm{CO}_{2}$ was determined by GC-MS (Agilent 7890B, USA) with 
$\mathrm{N}_{2}$ in air as an internal standard. Dissolved oxygen (DO) was determined by a DO meter (INESA JPB-607A, China) in an enlarged system $(10 \mathrm{mmol}$ DHA, reaction solution volume of $\sim 2 \mathrm{~mL})$ due to the large size of the electrode head $(1 \mathrm{~cm}$ in diameter). During the test, the DO electrode was first immersed $0.5 \mathrm{~cm}$ below the surface of the solution, and then the DO value was recorded after $30 \mathrm{~s}$ of stabilization. The relative abundance of FA, ${ }^{18} \mathrm{O}$-labeled FA, and their fragments were detected determined by gas chromatography-mass spectrometry (GC-MS, Shimadzu GCMS-QP2010Plus, Japan) with DB-FFAP column. The concentration of HO. was quantified by a chemical probe method using formic acid as the probe molecule ${ }^{31}$. More details are presented in Supplementary Methods.

Reusability of $\mathbf{M n O}_{2} / \mathbf{G o e}$ catalyst. The catalysts after reaction were filtered using $0.22 \mu \mathrm{m}$ PES membrane, washed with deionized water and dried overnight at $60^{\circ} \mathrm{C}$ in a vacuum oven for the next use. To offset the unavoidable catalyst mass loss during the recovery $(\sim 20-40 \%$ for each run), we performed 10 sets of parallel experiments at the first cycle to recover enough catalyst for subsequent cycles. The leaching percent is defined as the molar ratio between the loss of metal and initially, added metal component.

Scale-up of catalytic processes. For the continuous activity test, the reaction was carried out in a double-jacket tubular packed bed having dimensions of $100 \times 1.5 \mathrm{~cm}$ (height $\times$ diameter) (Supplementary Fig. 24), with the upflow of liquid through the packed layer of particles (mixture of 16 mesh silicon carbide with $2.0 \mathrm{~g}$ $1 \%-\mathrm{MnO}_{2}$ /Goe catalyst). The mixture of $1 \mathrm{mmol}$ DHA in $2 \mathrm{mmol} \mathrm{H}_{2} \mathrm{O}_{2}$ aqueous solution diluted to $10 \mathrm{wt} \%$ was pumped to the packed bed with a flow rate of $0.15 \mathrm{~mL} / \mathrm{min}$ ( $360 \mathrm{mmol} \mathrm{DHA} /$ day) and the reaction temperature was maintained at $25^{\circ} \mathrm{C}$. The batch reaction was scaled up 2500 times in equal condition of the original system and was carried out in a $1 \mathrm{~L}$ double-jacket kettle (catalyst $75 \mathrm{~mol}$, DHA $2.5 \mathrm{~mol}$, $500 \mathrm{~mL} 30 \mathrm{wt} \% \mathrm{H}_{2} \mathrm{O}_{2}$ aqueous, $25^{\circ} \mathrm{C}$, $400 \mathrm{rpm}, 24 \mathrm{~h}$ ) (Supplementary Fig. 25).

\section{Data availability}

The data that support the findings of this study are available from the corresponding author upon reasonable request.

Received: 19 May 2021; Accepted: 8 November 2021;

Published online: 25 November 2021

\section{References}

1. Cherubini, F. The biorefinery concept: using biomass instead of oil for producing energy and chemicals. Energy Conv. Manag. 51, 1412-1421 (2010).

2. Kunkes, E. L. et al. Catalytic conversion of biomass to monofunctional hydrocarbons and targeted liquid-fuel classes. Science 322, 417-421 (2008).

3. Centi, G. \& van Santen, R. A. Catalysis for Renewables: From Feedstock to Energy Production (John Wiley \& Sons, 2008).

4. Frkova, Z., Venditti, S., Herr, P. \& Hansen, J. Assessment of the production of biodiesel from urban wastewater-derived lipids. Resour. Conserv. Recycl. 162, 105044 (2020)

5. Zhao, H. et al. Raw biomass electroreforming coupled to green hydrogen generation. Nat. Commun. 12, 2008 (2021)

6. Wang, M., Liu, M., Lu, J. \& Wang, F. Photo splitting of bio-polyols and sugars to methanol and syngas. Nat. Commun. 11, 1083 (2020).

7. Gholami, Z., Abdullah, A. Z. \& Lee, K.-T. Dealing with the surplus of glycerol production from biodiesel industry through catalytic upgrading to polyglycerols and other value-added products. Renew. Sustain. Energy Rev. 39, 327-341 (2014).

8. Katryniok, B., Paul, S., Bellière-Baca, V., Rey, P. \& Dumeignil, F. Glycero dehydration to acrolein in the context of new uses of glycerol. Green. Chem. 12, 2079-2098 (2010).

9. Dodekatos, G., Schünemann, S. \& Tüysüz, H. Recent advances in thermo-, photo-, and electrocatalytic glycerol oxidation. ACS Catal. 8, 6301-6333 (2018).

10. Li, Y., Wei, X., Chen, L., Shi, J. \& He, M. Nickel-molybdenum nitride nanoplate electrocatalysts for concurrent electrolytic hydrogen and formate productions. Nat. Commun. 10, 5335 (2019).

11. Wang, Y. et al. Catalytic production of alanine from waste glycerol. Angew. Chem. Int. Ed. 59, 2289-2293 (2020).

12. Assary, R. S. \& Curtiss, L. A. Comparison of sugar molecule decomposition through glucose and fructose: a high-level quantum chemical study. Energy Fuels 26, 1344-1352 (2012).

13. Dai, X. et al. Sustainable co-synthesis of glycolic acid, formamides, and formates from 1,3-dihydroxyacetone by a $\mathrm{Cu} / \mathrm{Al}_{2} \mathrm{O}_{3}$ catalyst with a singleactive sites. Angew. Chem. Int. Ed. 58, 5251-5255 (2019).
14. Zhang, J., Liu, X., Sun, M., Ma, X. \& Han, Y. Direct conversion of cellulose to glycolic acid with a phosphomolybdic acid catalyst in a water medium. ACS Catal. 2, 1698-1702 (2012).

15. Zhou, Y., Shen, Y. \& Xi, J. Seed-mediated synthesis of PtxAuy@Ag electrocatalysts for the selective oxidation of glycerol. Appl. Catal. B: Environ. 245, 604-612 (2019).

16. Nakagawa, Y., Sekine, D., Obara, N., Tamura, M. \& Tomishige, K. Oxidative C -C cleavage of ketols over vanadium-carbon catalysts. ChemCatChem $\mathbf{9}$, 3412-3419 (2017)

17. Bulushev, D. A. \& Ross, J. R. H. Towards sustainable production of formic acid. ChemSusChem 11, 821-836 (2018).

18. Becker, J., Lange, A., Fabarius, J. \& Wittmann, C. Top value platform chemicals: bio-based production of organic acids. Curr. Opin. Biotechnol. 36, 168-175 (2015).

19. Pierre, J. L. \& Fontecave, M. Iron and activated oxygen species in biology: the basic chemistry. Biometals 12, 195-199 (1999).

20. Gligorovski, S., Strekowski, R., Barbati, S. \& Vione, D. Environmental Implications of Hydroxyl Radicals (•OH). Chem. Rev. 115, 13051-13092 (2015).

21. Sivaguru, P., Wang, Z., Zanoni, G. \& Bi, X. Cleavage of carbon-carbon bonds by radical reactions. Chem. Soc. Rev. 48, 2615-2656 (2019).

22. Shen, X., Xin, Y., Liu, H. \& Han, B. Product-oriented direct cleavage of chemical linkages in lignin. ChemSusChem 13, 4367-4381 (2020).

23. Jiao, X. et al. Photocatalytic conversion of waste plastics into $\mathrm{C}_{2}$ fuels under simulated natural environment conditions. Angew. Chem. Int. Ed. 59, 15497-15501 (2020).

24. Li, X.-y, Cui, Y.-h, Feng, Y.-j, Xie, Z.-m \& Gu, J.-D. Reaction pathways and mechanisms of the electrochemical degradation of phenol on different electrodes. Water Res. 39, 1972-1981 (2005).

25. Zhou, Y., Zhang, L. \& Wang, W. Direct functionalization of methane into ethanol over copper modified polymeric carbon nitride via photocatalysis. Nat. Commun. 10, 506 (2019).

26. Xing, $\mathrm{Y}$. et al. $\mathrm{Fe} / \mathrm{Fe} 3 \mathrm{C}$ boosts $\mathrm{H}_{2} \mathrm{O}_{2}$ utilization for methane conversion overwhelming $\mathrm{O}_{2}$ generation. Angew. Chem. Int. Ed. 60, 8889-8895 (2021).

27. Arunan, E. The $\mathrm{C}-\mathrm{C}$ bond is stronger than the $\mathrm{C}-\mathrm{Cl}$ bond in $\mathrm{CH}_{3} \mathrm{COCl} . J$. Phys. Chem. A. 101, 4838-4839 (1997).

28. Chen, S.-H. \& Hiramatsu, H. Tautomer structures in ketose-aldose transformation of 1,3-dihydroxyacetone studied by infrared electroabsorption spectroscopy. J. Phys. Chem. B. 123, 10663-10671 (2019).

29. Yamaguchi, S. et al. Mechanistic studies on the cascade conversion of 1,3dihydroxyacetone and formaldehyde into $\alpha$-hydroxy- $\gamma$-butyrolactone. ChemSusChem 8, 853-860 (2015).

30. Lin, S.-S. \& Gurol, M. D. Catalytic decomposition of hydrogen peroxide on iron oxide: kinetics, mechanism, and implications. Environ. Sci. Technol. 32, 1417-1423 (1998).

31. Kwan, W. P. \& Voelker, B. M. Rates of hydroxyl radical generation and organic compound oxidation in mineral-catalyzed Fenton-like systems. Environ. Sci. Technol. 37, 1150-1158 (2003).

32. Laberty, C. \& Navrotsky, A. Energetics of stable and metastable lowtemperature iron oxides and oxyhydroxides. Geochim. Cosmochim. Acta 62, 2905-2913 (1998)

33. Alvarez, M., Rueda, E. H. \& Sileo, E. E. Simultaneous incorporation of Mn and $\mathrm{Al}$ in the goethite structure. Geochim. Cosmochim. Acta 71, 1009-1020 (2007).

34. Manceau, A. et al. Crystal chemistry of trace elements in natural and synthetic goethite. Geochim. Cosmochim. Acta 64, 3643-3661 (2000).

35. Navrotsky, A., Mazeina, L. \& Majzlan, J. Size-driven structural and thermodynamic complexity in iron oxides. Science 319, 1635 (2008).

36. Sileo, E. E., Alvarez, M. \& Rueda, E. H. Structural studies on the manganese for iron substitution in the synthetic goethite-jacobsite system. Int. J. Inorg. Mater. 3, 271-279 (2001)

37. Ye, X., Cui, Y., Qiu, X. \& Wang, X. Selective oxidation of benzene to phenol by Fe-CN/TS-1 catalysts under visible light irradiation. Appl. Catal. B: Environ. 152-153, 383-389 (2014).

38. Deng, D. et al. A single iron site confined in a graphene matrix for the catalytic oxidation of benzene at room temperature. Sci. Adv. 1, e1500462 (2015).

39. Wang, D., Wang, M. \& Li, Z. Fe-based metal-organic frameworks for highly selective photocatalytic benzene hydroxylation to phenol. ACS Catal. 5, 6852-6857 (2015).

40. ElMetwally, A. E., Eshaq, G., Yehia, F. Z., Al-Sabagh, A. M. \& Kegnæs, S. Iron oxychloride as an efficient catalyst for selective hydroxylation of benzene to phenol. ACS Catal. 8, 10668-10675 (2018).

41. Zhang, M. et al. Metal (hydr)oxides@polymer core-shell strategy to metal single-atom materials. J. Am. Chem. Soc. 139, 10976-10979 (2017).

42. Lu, E. et al. Selective hydroxylation of benzene to phenol over Fe nanoparticles encapsulated within N-doped carbon shells. ACS Appl. Nano Mater. 3, 9192-9199 (2020).

43. Bai, S., Xu, Y., Wang, P., Shao, Q. \& Huang, X. Activating and converting $\mathrm{CH}_{4}$ to $\mathrm{CH}_{3} \mathrm{OH}$ via the $\mathrm{CuPdO}_{2} / \mathrm{CuO}$ nanointerface. ACS Catal. 9, 6938-6944 (2019). 
44. Kapkowski, M. et al. SiO2-, Cu-, and Ni-supported Au nanoparticles for selective glycerol oxidation in the liquid phase. J. Catal. 319, 110-118 (2014).

45. Sarkar, B. et al. $\mathrm{Cu}$ nanoclusters supported on nanocrystalline $\mathrm{SiO} 2-\mathrm{MnO} 2$ : a bifunctional catalyst for the one-step conversion of glycerol to acrylic acid. Chem. Commun. 50, 9707-9710 (2014).

46. Wang, X., Wu, G., Jin, T., Xu, J. \& Song, S. Selective oxidation of glycerol using $3 \% \mathrm{H}_{2} \mathrm{O}_{2}$ catalyzed by supported nano-Au catalysts. Catalysts $\mathbf{8}, 505$ (2018).

47. Reid, R. Electrogeneration of Hydrogen Peroxide for Applications in Water/ Wastewater Treatment (University of Waterloo, 2017).

48. Russo, V., Tesser, R., Santacesaria, E. \& Di Serio, M. Chemical and technical aspects of propene oxide production via hydrogen peroxide (HPPO process). Ind. Eng. Chem. Res. 52, 1168-1178 (2013).

49. Goyal, R., Singh, O., Agrawal, A., Samanta, C. \& Sarkar, B. Advantages and limitations of catalytic oxidation with hydrogen peroxide: from bulk chemicals to lab scale process. Catal. Rev. 1-57, https://doi.org/10.1080/ $01614940.2020 .1796190(2020)$

50. Gozin, M., Weisman, A., Ben-David, Y. \& Milstein, D. Activation of a carbon-carbon bond in solution by transition-metal insertion. Nature 364 699-701 (1993).

51. Morcillo, S. P. \& Radical-Promoted, C. -C. Bond cleavage: a deconstructive approach for selective functionalization. Angew. Chem. Int. Ed. 58, 14044-14054 (2019).

52. Suggs, J. W. \& Jun, C. H. Directed cleavage of carbon-carbon bonds by transition metals: the a-bonds of ketones. J. Am. Chem. Soc. 106, 3054-3056 (1984).

53. Broughton, D. B. \& Wentworth, R. L. Mechanism of decomposition of hydrogen peroxide solutions with manganese dioxide. I. J. Am. Chem. Soc. 69, 741-744 (1947).

54. Amstaetter, K., Borch, T., Larese-Casanova, P. \& Kappler, A. Redox transformation of arsenic by $\mathrm{Fe}(\mathrm{II})$-activated goethite ( $\alpha-\mathrm{FeOOH})$. Environ. Sci. Technol. 44, 102-108 (2010).

55. Klewicki, J. K. \& Morgan, J. J. Kinetic behavior of Mn(III) complexes of pyrophosphate, EDTA, and citrate. Environ. Sci. Technol. 32, 2916-2922 (1998).

56. Barnese, K., Gralla, E. B., Valentine, J. S. \& Cabelli, D. E. Biologically relevant mechanism for catalytic superoxide removal by simple manganese compounds. Proc. Natl Acad. Sci. USA 109, 6892 (2012).

57. Takashima, T., Hashimoto, K. \& Nakamura, R. Inhibition of charge disproportionation of $\mathrm{MnO}_{2}$ electrocatalysts for efficient water oxidation under neutral conditions. J. Am. Chem. Soc. 134, 18153-18156 (2012).

58. McElroy, W. J. \& Waygood, S. J. Oxidation of formaldehyde by the hydroxyl radical in aqueous solution. J. Chem. Soc., Faraday Trans. 87, 1513-1521 (1991).

59. Monod, A., Chebbi, A., Durand-Jolibois, R. \& Carlier, P. Oxidation of methanol by hydroxyl radicals in aqueous solution under simulated cloud droplet conditions. Atmos. Environ. 34, 5283-5294 (2000).

60. Allen, H. M. et al. Kinetics and product yields of the $\mathrm{OH}$ initiated oxidation of hydroxymethyl hydroperoxide. J. Phys. Chem. A 122, 6292-6302 (2018).

61. Pau, M. Y. M., Lipscomb, J. D. \& Solomon, E. I. Substrate activation for $\mathrm{O}_{2}$ reactions by oxidized metal centers in biology. Proc. Natl Acad. Sci. USA 104, 18355 (2007).

62. Bothe, E. \& Schulte-Frohlinde, D. The bimolecular decay of the $\alpha$ hydroxymethylperoxyl radicals in aqueous solution. Z. f.ür. Naturforsch. B 33, 786-788 (1978).

63. Vacque, V., Sombret, B., Huvenne, J. P., Legrand, P. \& Suc, S. Characterisation of the O.O peroxide bond by vibrational spectroscopy. Spectrochim. Acta Part A: Mol. Biomol. Spectrosc. 53, 55-66 (1997).

64. Buxton, G. V., Greenstock, C. L., Helman, W. P. \& Ross, A. B. Critical review of rate constants for reactions of hydrated electrons, hydrogen atoms, and hydroxyl radicals $(\cdot \mathrm{OH} / \cdot \mathrm{O}-$ in aqueous solution. J. Phys. Chem. Ref. Data 17, 513-886 (1988).

65. Schwertmann, U. \& Cornell, R. M. Iron Oxides in the Laboratory: Preparation and Characterization (John Wiley \& Sons, 2008).

66. Anschutz, A. J. \& Penn, R. L. Reduction of crystalline iron(III) oxyhydroxides using hydroquinone: influence of phase and particle size. Geochem. Trans. 6, 60 (2005).
67. Gerth, J. Unit-cell dimensions of pure and trace metal-associated goethites. Geochim. Cosmochim. Acta 54, 363-371 (1990).

68. Hu, J. L. \& Chen, G. Fast removal and recovery of $\mathrm{Cr}(\mathrm{VI})$ using surface-modified jacobsite $\left(\mathrm{MnFe}_{2} \mathrm{O}_{4}\right)$ nanoparticles. Langmuir 21, 11173-11179 (2005).

69. Frisch, M. Gaussian09. http://www.gaussian.com (2009).

70. Wu, P.-W., Chang, C.-C. \& Chou, S.-S. Determination of formaldehyde in cosmetics by HPLC method and acetylacetone method. J. Food Drug Anal. 11, 5 (2003).

71. Sellers, R. M. Spectrophotometric determination of hydrogen peroxide using potassium titanium(IV) oxalate. Analyst 105, 950-954 (1980).

\section{Acknowledgements}

This work was supported by grants from the National Key Research and Development Program of China (2019YFC1906700), the National Natural Science Foundation of China $(219611322025,21876049,91834301)$. We also thank mineral collector Qinglang Luo (Guilin Qinglang Mineral Specimens Co., Ltd.) for providing the natural minerals and his valuable discussion about the mineralogy, Dr. Casey Finnerty (University of California, Berkeley) for polishing the language of the manuscript, and Shiyanjia Lab (www.shiyanjia.com) for the assistance of HRTEM test.

\section{Author contributions}

J.W. dominantly conducted the experimental work, co-conceived the concept of the presented work, and co-wrote the manuscript. X.D. set up the measurement method of the system. X.D. and J.R. co-conducted the ATR-FTIR experiment. H.W. and H.L. coconceived the concept of the presented work. A.B., F.S., M.G., and X.Y. co-conceived the concept of the presented work and co-wrote the manuscript.

\section{Competing interests}

The authors declare no competing interests.

\section{Additional information}

Supplementary information The online version contains supplementary material available at https://doi.org/10.1038/s41467-021-27240-5.

Correspondence and requests for materials should be addressed to Angelika Brückner or Xuejing Yang.

Peer review information Nature Communications thanks Yu Han and the other, anonymous reviewer(s) for their contribution to the peer review of this work. Peer reviewer reports are available.

Reprints and permission information is available at http://www.nature.com/reprints

Publisher's note Springer Nature remains neutral with regard to jurisdictional claims in published maps and institutional affiliations.

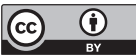

Open Access This article is licensed under a Creative Commons Attribution 4.0 International License, which permits use, sharing, adaptation, distribution and reproduction in any medium or format, as long as you give appropriate credit to the original author(s) and the source, provide a link to the Creative Commons license, and indicate if changes were made. The images or other third party material in this article are included in the article's Creative Commons license, unles indicated otherwise in a credit line to the material. If material is not included in the article's Creative Commons license and your intended use is not permitted by statutory regulation or exceeds the permitted use, you will need to obtain permission directly from the copyright holder. To view a copy of this license, visit http://creativecommons.org/ licenses/by/4.0/

(c) The Author(s) 2021 